\title{
Utility of models of the gastrointestinal tract for assessment of the digestion and absorption of engineered nanomaterials released from food matrices
}

David E. Lefebvre, Koen Venema, Lourdes Gombau, Luis G. Valerio Jr, Jayadev Raju, Genevieve S. Bondy, Hans Bouwmeester, R. Paul Singh, Amy J. Clippinger, Eva-Maria Collnot, Rekha Mehta \& Vicki Stone

To cite this article: David E. Lefebvre, Koen Venema, Lourdes Gombau, Luis G. Valerio Jr, Jayadev Raju, Genevieve S. Bondy, Hans Bouwmeester, R. Paul Singh, Amy J. Clippinger, EvaMaria Collnot, Rekha Mehta \& Vicki Stone (2015) Utility of models of the gastrointestinal tract for assessment of the digestion and absorption of engineered nanomaterials released from food matrices, Nanotoxicology, 9:4, 523-542, DOI: 10.3109/17435390.2014.948091

To link to this article: https://doi.org/10.3109/17435390.2014.948091

\section{(c) 2014 The Author(s). Published by Taylor \& Francis.}

Submit your article to this journal $\widetilde{ }$

View related articles

Citing articles: 32 View citing articles
曲 Published online: 14 Aug 2014.

山 Article views: 29126

View Crossmark data 


\title{
Utility of models of the gastrointestinal tract for assessment of the digestion and absorption of engineered nanomaterials released from food matrices
}

\author{
David E. Lefebvre ${ }^{1}$, Koen Venema ${ }^{2}$, Lourdes Gombau ${ }^{3}$, Luis G. Valerio $\mathrm{Jr}^{4}$, Jayadev Raju ${ }^{1}$, Genevieve S. Bondy ${ }^{1}$, \\ Hans Bouwmeester ${ }^{5}$, R. Paul Singh ${ }^{6}$, Amy J. Clippinger ${ }^{7}$, Eva-Maria Collnot ${ }^{8}$, Rekha Mehta ${ }^{1}$, and Vicki Stone ${ }^{9}$ \\ ${ }^{1}$ Regulatory Toxicology Research Division, Food Directorate, Health Canada, Ottawa, Canada, ${ }^{2}$ Beneficial Microbes Consultancy, Wageningen, \\ Netherlands, ${ }^{3}$ Leitat Technological Center, Barcelona, Spain, ${ }^{4}$ Office of Pharmaceutical Science, Center for Drug Evaluation and Research, US Food \\ and Drug Administration, Silver Spring, MD, USA, ${ }^{5}$ RIKILT - Wageningen UR, Wageningen, Netherlands, ${ }^{6}$ Department of Biological and Agricultural \\ Engineering, University of California, Davis, CA, USA, ${ }^{7}$ PETA International Science Consortium, Ltd., London, UK, ${ }^{8}$ URSAPHARM Industries, \\ Saarbrucken, Germany, and ${ }^{9}$ School of Life Sciences, Heriot-Watt University, Edinburgh, UK
}

\begin{abstract}
Engineered metal/mineral, lipid and biochemical macromolecule nanomaterials (NMs) have potential applications in food. Methodologies for the assessment of NM digestion and bioavailability in the gastrointestinal tract are nascent and require refinement. A working group was tasked by the International Life Sciences Institute NanoRelease Food Additive project to review existing models of the gastrointestinal tract in health and disease, and the utility of these models for the assessment of the uptake of NMs intended for food. Gastrointestinal digestion and absorption could be addressed in a tiered approach using in silico computational models, in vitro non-cellular fluid systems and in vitro cell culture models, after which the necessity of ex vivo organ culture and in vivo animal studies can be considered. Examples of NM quantification in gastrointestinal tract fluids and tissues are emerging; however, few standardized analytical techniques are available. Coupling of these techniques to gastrointestinal models, along with further standardization, will further strengthen methodologies for risk assessment.
\end{abstract}

\author{
Keywords \\ Alimentary canal, bioaccessibility, \\ bioavailability, nanotechnology
}

\section{History}

Received 29 January 2014

Revised 9 July 2014

Accepted 9 July 2014

Published online 13 August 2014

\section{Introduction}

Nanotechnology approaches are allowing the development of deliberately engineered nanomaterials (NMs), presenting promising new applications for conventional foods, such as the enhancement of texture, color, flavor, nutrient stability and food packaging safety (Sozer \& Kokini, 2009). Some NMs possess unique properties, and novel uses in food or food contact materials could require a separate risk assessment from the equivalent bulk and ionic counterparts. Thus, there is heightened interest in the identification, validation and standardization of scientific methodologies to assess the uptake, and therefore internal absorbed dose, of NMs that are relevant to human dietary sources (Bouwmeester et al., 2009; Card et al., 2011). Identification and quantification of changes to these materials during digestion in the gastrointestinal (GI) tract lumen, and of absorption through the GI tract epithelium, can be important in their risk assessment (Cockburn et al., 2012; Dekkers et al., 2011; Hagens et al., 2007). The oral absorption of drugs in the nanometer range was previously reviewed (Gamboa \& Leong,

This is an Open Access article distributed under the terms of the Creative Commons Attribution License (http://creativecommons.org/Licenses/by/4.0/), which permits unrestricted use, distribution, and reproduction in any medium, provided the original work is properly cited.

Correspondence: Vicki Stone, School of Life Sciences, Heriot-Watt University, Riccarton campus, Edinburgh EH14 4AS, UK. Tel: +44 131 451 3460. E-mail: v.stone@ hw.ac.uk
2013; Shahbazi \& Santos, 2013). However, the utility of digestion and absorption models of the GI tract for the evaluation of foodrelevant NMs has not been assessed.

The NanoRelease Food Additive project, coordinated by the International Life Sciences Institute (ILSI) Research Foundation Center for Risk Science Innovation and Application, is reviewing and developing methods to measure the release and uptake of intentionally engineered NMs from food matrices in the GI tract (Alger et al., 2014; Noonan et al., 2014; Singh et al., 2014; Szakal et al., 2014a,b). Food is naturally chemically complex and consists of biological polymers with dimensions in the nanometer size range. To avoid the complication of integrating the different jurisdictional definitions, or lack thereof, that distinguishes engineered NMs from chemicals found naturally in food, the NanoRelease Food Additive project defined three broad categories of engineered nanomaterials: metal/mineral-based NMs, soft lipid NMs and solid biochemical macromolecule NMs including new proteins, polysaccharides and nucleic acids (Yada et al., 2014). A specific size range was not defined to allow the identification of methods relevant to a broad range of sizes. Elsewhere, the NanoRelease Food Additive project reviewed the influence of the physico-chemical properties of these materials on their stability in human gastrointestinal fluids and their permeability through mucus and epithelial cells (Szakal et al., 2014a). That work sets the stage for this review from the NanoRelease Food Additive project to identify models of the mammalian GI tract that can be used for the assessment of the fate of food-relevant NMs. 
For food travelling through the GI tract, the bioaccessible fraction is the proportion of a component that is released from the food matrix into the digestive juice (Rein et al., 2013). Then, the bioaccessible fraction has the potential to either be digested or remain intact, and either be absorbed through the GI tract wall or be excreted. Bioavailability, or fraction absorbed, refers to the portion of the bioaccessible fraction that crosses through GI epithelial cells into lymph and blood. For a NM, bioavailability may refer either to the fraction of particles still in the nanometer size range, or to the atoms that make up the NMs. Another key definition for the topics covered in this review is the distinction of particle aggregation and agglomeration. In an aggregate, the primary particles are tightly bound by chemical forces, such that disintegration is very difficult even when applying physical forces. Agglomeration is the loose association of primary particles by weak forces such as van der Waals forces. Agglomerates can be disintegrated by physical forces such as agitation and sonication. The scope of this article does not include models of systemic distribution, metabolism, elimination, toxicology or nutrition. Rather, the objectives were to (a) identify models of the human GI tract that are used to quantify the digestion and absorption of conventional chemicals in states of health and disease, (b) consider the relevance of the models to NM digestion and absorption pathways, (c) provide examples where foodrelevant NMs have been tested and (d) identify research, validation and standardization needs specific to the assessment of food-relevant NMs.

\section{Models of the healthy gastrointestinal tract}

Various models closely simulate human physiology and have been used for decades to assess the solubility, digestion and epithelial permeability of conventional food and drug components in the buccal cavity, stomach, small intestine and colon. The potential utility of these experiments in the assessment of food-relevant NMs is detailed below.

\section{In vivo animal models}

The processes of digestion and absorption of nutrients are similar in humans and other mammalian species. Therefore, toxico-kinetic studies in animals have historically been used as one way of assessing these parameters for conventional chemicals (Table 1).
However, ethical consideration and approval is required for the use of animals. The concepts of replacement, reduction and refinement have formed the basic tenants of animal welfare in experimentation since their introduction by Russell and Burch in 1959 (Liebsch et al., 2011). Replacement involves the use of in vitro or in silico models instead of animals, when such methods are available and sufficiently predictive of outcomes in humans. Reduction maximizes data from the lowest number of animals possible, without compromising the required statistical strength of the study. Reduction strategies include completing in vitro mechanistic studies before deciding if further animal testing is required, the maintenance of public databases to share nonproprietary historical in vivo information (e.g. the Nanomaterial Registry at https://www.nanomaterialregistry.org/), and forming consortia in order to avoid duplicative testing. Refinements incorporate advances in animal husbandry and scientific procedures to reduce the pain and suffering experienced by animals. Examples include species-specific enrichment and housing conditions, the use of non-invasive techniques, appropriate pain relief and humane endpoints (OECD, 2000).

The scientific quality and potential extended usefulness of in vivo animal studies is improved with standardized protocols. The Organization for Economic Co-operation and Development (OECD) maintains guidelines for toxico-kinetic feeding studies in animals, including rodents. With these protocols, test compounds are orally administered either in the food or drinking water, or via single or repeated gastric gavage. Whereas dosing in food or water is more realistic, it might be less accurate. The gavage procedure can increase accuracy. However, limitations include the bolus effect, lack of exposure of the buccal cavity, lack of the physical chewing forces that are encountered in humans, potential tissue damage, potential accidental aspiration into the lungs, stress, nonspecific binding of the test substance to the gavage tubing and abnormal food transit times (Powell et al., 2010). Following administration, detection methods scan for test material residues in feces, blood, lymph and GI tissues. It is not yet known if it will be necessary to modify the current OECD guidelines for toxicokinetics studies to accommodate NMs (OECD, 2010) and it is currently not clear whether administration via gavage versus introduction into food or water is more appropriate. Despite this, some oral feeding studies in the literature demonstrate that several toxico-kinetic parameters can be modeled for NMs.

Table 1. In vivo techniques that have been commonly used to assess the digestion and absorption of conventional chemicals in the gastrointestinal tract, and could be relevant to the assessment of NMs.

\begin{tabular}{|c|c|c|c|c|}
\hline Model & Species & $\begin{array}{c}\text { Characteristics and } \\
\text { applications for } \\
\text { conventional chemicals }\end{array}$ & Limitations & $\begin{array}{c}\text { References on } \\
\text { conventional uses }\end{array}$ \\
\hline $\begin{array}{l}\text { Toxicokinetic feeding or } \\
\text { gavage studies }\end{array}$ & $\begin{array}{l}\text { Primarily rat, mouse, ham- } \\
\text { ster or guinea pig, unless } \\
\text { another species such as } \\
\text { pigs or primates is } \\
\text { required for regulatory } \\
\text { purposes }\end{array}$ & $\begin{array}{l}\text { Assesses systemic absorp- } \\
\text { tion, excretion, and per- } \\
\text { sistence of the chemical }\end{array}$ & $\begin{array}{l}\text { Gavage does not represent a } \\
\text { realistic exposure scenario; } \\
\text { recovery and quantification } \\
\text { of administered compounds } \\
\text { in animal tissues is a chal- } \\
\text { lenge; some species do not } \\
\text { accurately predict chemical } \\
\text { bioavailability in humans }\end{array}$ & OECD (2010) \\
\hline In situ intestinal perfusion & Rats or other species & $\begin{array}{l}\text { Cannulation of both ends of } \\
\text { a segment of the gastro- } \\
\text { intestinal tract in a live, } \\
\text { anesthetized subject } \\
\text { allows infusion of a } \\
\text { solution and collection } \\
\text { of the perfusate at the } \\
\text { distal end; determines } \\
\text { permeability through the } \\
\text { gastrointestinal tract wall }\end{array}$ & $\begin{array}{l}\text { Requires surgery and anesthe- } \\
\text { sia; can result in abnormal } \\
\text { transit times or paralysis of } \\
\text { the bowel; digestion is not } \\
\text { modeled; not a high- } \\
\text { throughput model }\end{array}$ & $\begin{array}{l}\text { Lennernas et al. (1997), } \\
\text { Kim et al. (2006) }\end{array}$ \\
\hline
\end{tabular}


Silver nanoparticles (NPs) are a unique example with regard to their chemistry, dissolution and interaction. The absorption of $14 \mathrm{~nm}$ silver NPs has been indirectly characterized following a 28-day repeated oral exposure study in rats, and was compared with silver ion exposure (Loeschner et al., 2011). The silver atoms that made up both silver sources were detected in the intestinal lamina propria and submucosa of exposed rats. Interestingly, electron microscopy energy dispersive X-ray emission spectroscopy detected nanometer-sized granules, containing silver, selenium and sulfur, in the intestinal basal lamina propria of rats exposed to either the NPs or the ions. The level of silver atoms in the stomach and intestinal wall, normalized to silver exposure dose, was significantly higher in the ion-exposed rats than in the NP-exposed rats (van der Zande et al., 2012). Levels of silver atoms in the feces represented $99 \%$ of the administered dose. A single oral exposure of rats to $8 \mathrm{~nm}$ citrate-coated silver NPs, using OECD toxico-kinetic guideline 417, confirmed that most of the silver content was excreted via feces within $24 \mathrm{~h}$ of the treatment (Park et al., 2011). Bioavailability, quantified as blood concentration of silver, was $1.2 \%$ following treatment with $1 \mathrm{mg} / \mathrm{kg}$ body weight NPs and $4.2 \%$ following treatment with $10 \mathrm{mg} / \mathrm{kg}$. Pioneering work in this field investigated other insoluble particles, such as $500 \mathrm{~nm}$ rutile titanium dioxide, and demonstrated uptake by gut-associated lymphoid tissue (Jani et al., 1994). Other NM categories such as vitamin B1-coated NPs have also been tested in vivo (Salman et al., 2007). Similarly, Yuan et al. (2007) characterized fluorescently labeled engineered lipid-based particles following intragastric administration to rats by gavage. Fluorescence in blood and lymph was detected by spectrophotometry, as an indirect measure of particle absorption through the GI tract. The $202 \mathrm{~nm}$ solid-lipid NPs modified with stearic acid showed 30\% absorption efficiency into the bloodstream during the $48 \mathrm{~h}$ following administration. The fluorescent label alone was not absorbed, ruling out false-positive absorption of label leaked from the particles.

Together, these studies provide a useful stage in addressing the need to better quantify uptake of NM from the gastrointestinal tract into blood over time, and their subsequent biodistribution. More work is required to extend this information to a wider array of NMs with different physicochemical properties, including those for which solubility may be an issue.

In situ perfusion models in live, anesthetized subjects can specifically quantify the permeability of a compound through a segment of the gastrointestinal tract over the course of several hours. Rat intestinal permeability coefficients for chemicals have been shown to correlate well with those in humans; particularly for substances that are passively transported (Lennernas, 2007). It is not known if this will hold true for NMs. However, relevant experiments are emerging. Lipid-based NMs were studied in situ with ligated intestinal jejunum loops; an approach similar to perfusion (Yuan et al., 2013). Following necropsy, microscopy with gut sections qualitatively demonstrated that $200 \mathrm{~nm}$ solidlipid particles modified with polyethylene glycol were able to penetrate through the mucus coating the epithelial cells and gain contact with those cells, positioning them for absorption. Unmodified particles were trapped in the mucus above the epithelium. Fluorescence from polysaccharide macromoleculebased $290 \mathrm{~nm}$ chitosan particles administered in situ in rats were observed in intestinal enterocyte cells, in Peyer's patches, and in the underlying lamina propria (Behrens et al., 2002). More work is required to identify why some NM become trapped in the mucus layer while others appear to penetrate effectively.

A major advantage of in vivo studies is the presence of intact anatomical features and physiological processes. The absorption of conventional chemicals is often similar to humans; however, discrepancies can result from the differences in anatomy, food transit times, digestive enzymes, transporters and metabolism (Kim et al., 2006). The differences between humans and rodents in terms of uptake and how such parameters modify uptake are not yet understood for NM. When alternative in vitro and in silico models were not available for particular purposes, in vivo animal studies were used as the status quo method of predicting human absorption. Classical in vivo and in situ toxico-kinetic study designs may be valid to study the uptake of NMs in GI tissues. However, most relevant analytical tools will need to be validated and adopted internationally in order to be able to quantify the uptake. This presents an opportunity for simultaneous validation of the analytical tools with human-relevant in vitro or in silico methods that show potential for the replacement of current animal testing methods.

\section{Ex vivo tissue models}

Ex vivo models use tissue samples that are excised from an anesthetized organism and maintained under conditions supporting certain aspects of normal function. Ex vivo methods are sometimes used to assess chemical permeability (Table 2). Ex vivo gastrointestinal models suffer the disadvantage of lacking digestive juices. However, they are higher throughput than in vivo or in situ studies. The following paragraphs summarize how $e x$ vivo models have been applied to study NMs.

The everted gut sac model was used to quantify the permeability of radiolabeled $500 \mathrm{~nm}$ tomato lectin-coated polystyrene particles (Carreno-Gomez et al., 1999). At an administered concentration of $20 \mu \mathrm{g} / \mathrm{mL}$, the particles transferred through the gut wall to the serosal fluid at a rate of $22.7 \mathrm{ng} / \mathrm{mg}$ tissue protein per hour. However, overall this represented only a small percentage of the administered material. The kinetics of particle and agglomerate sedimentation was not determined. The effects of NM agglomeration and sedimentation on ex vivo models such as the gut sac need to be investigated. In another study, segments of rat small intestine were incubated with fluorescent chitosan. Mucus adhesion, penetration and particle disintegration were studied by fluorescence image visualization of tissue slices and by fluorescence quantification in mucus scraped from the tissue (Dunnhaupt et al., 2011). There was significantly greater mucoadhesion and stability of thiol-conjugated than non-thiolated chitosan. The non-thiolated particles more readily penetrated through the mucus, contacted the underlying epithelial cells and disintegrated. Going one step further, mucoadhesion and tissue permeation of larger $800 \mathrm{~nm}$ fluorescent chitosans with different surface chemistries was quantified on isolated rat intestinal mucosa using a Franz diffusion cell (Sandri et al., 2007). Adhesion to the tissue was indirectly quantified from the residual fluorescence in the donor and receiver buffers following exposure. Particles with higher mucoadhesion were identified by their higher residence time on the intestinal mucosa, but they had lower penetration through the tissue, as confirmed by microscopy. Again, the physicochemical characteristics of NM that influence their interaction with mucus and hence epithelial penetration requires further investigation. Such models provide a useful tool as they are more easily controlled than in vivo studies, but they still include the full complement of cell types within the barrier structure.

The analysis of specific segments of the GI tract provides a mechanistic focus, but is limited by the capacity to collect and maintain viable tissues from the area of interest (Lennernas, 2007). The lack of digestive enzymes and short viability time of ex vivo tissues limit their utility for the prediction of absorption in vivo. However, they are higher throughput than in vivo studies and they have allowed qualitative and quantitative determination of mucoadhesion and permeability of NMs through the intestinal 
Table 2. Ex vivo tissue models that have been commonly used to assess the absorption of conventional chemicals through the gastrointestinal tract, and that could be relevant to the assessment of NMs.

\begin{tabular}{|c|c|c|c|c|}
\hline Model & $\begin{array}{l}\text { Species and tissue } \\
\text { of origin }\end{array}$ & $\begin{array}{l}\text { Characteristics and } \\
\text { applications for conventional } \\
\text { chemicals }\end{array}$ & Limitations & $\begin{array}{c}\text { References on } \\
\text { conventional uses }\end{array}$ \\
\hline Everted gut sac & $\begin{array}{l}\text { Excised intestinal seg- } \\
\text { ments from rat or } \\
\text { other species }\end{array}$ & $\begin{array}{l}\text { The intestine is everted, ligated } \\
\text { at both ends and cultured in } \\
\text { an oxygenated nutrient } \\
\text { solution; adhesion of an } \\
\text { administered compound to } \\
\text { the outer mucus layer and } \\
\text { permeability through the } \\
\text { tissue to the inside of the sac } \\
\text { is measured; relatively } \\
\text { simple and inexpensive } \\
\text { methodology }\end{array}$ & $\begin{array}{l}\text { Careful tissue handling is } \\
\text { critical to avoid mech- } \\
\text { anical damage; appro- } \\
\text { priate culture conditions } \\
\text { must be used to maintain } \\
\text { tissue viability; the static } \\
\text { fluid in the serosal com- } \\
\text { partment does not } \\
\text { accurately model in vivo } \\
\text { circulation }\end{array}$ & Alam et al. (2012) \\
\hline $\begin{array}{l}\text { Transmucosal perfusion } \\
\text { through isolated mucosa }\end{array}$ & $\begin{array}{l}\text { Mucosal layer isolated } \\
\text { from biopsies from } \\
\text { the buccal cavity or } \\
\text { intestine of rat, pig or } \\
\text { other species }\end{array}$ & $\begin{array}{l}\text { Perfusion device with a donor } \\
\text { and receiver chamber, such } \\
\text { as an Ussing chamber or } \\
\text { Franz diffusion cell, deter- } \\
\text { mines permeability through } \\
\text { the mucosal layer; results } \\
\text { compare favorably to human } \\
\text { data, particularly for pas- } \\
\text { sively absorbed substances }\end{array}$ & $\begin{array}{l}\text { Tissue viability declines } \\
\text { rapidly }\end{array}$ & $\begin{array}{l}\text { Roblegg et al. (2012), } \\
\text { Rozehnal et al. (2012) }\end{array}$ \\
\hline
\end{tabular}

wall. Results for conventional chemicals compare well to human data, but further work is required with NMs.

\section{In vitro cell culture models}

In vitro cell models are one of several options for the replacement of live animal methods. They allow the screening of specific mechanisms of epithelial permeability, potentially in a highthroughput manner. The most frequently used in vitro models are discussed below.

Primary epithelial cells freshly isolated from the GI tract are not widely used to study the absorption of chemicals or NMs because they have a restricted lifespan in culture, and they are generally unable to form an organized monolayer (Chopra et al., 2010). Effective in vitro systems often use immortalized cell lines that can form an adherent monolayer reflecting certain characteristics of the epithelium of the GI tract. Furthermore, monolayers grown to confluence on a semi-permeable membrane, separating two chambers, are used to assess the permeability of a compound from the donor to the receiver chamber (Youdim et al., 2003). This system simulates bioavailability from the gut lumen to the circulating basolateral lymph. Although cells of human origin are preferable for human risk assessment, animal cell lines can also model human biology.

Various cell lines originating from different segments of the GI tract are commonly used in chemical risk assessment (Table 3). Among the variety that are available, intestinal Caco- 2 cells have been the most commonly used (Christensen et al., 2012; Miret et al., 2004). They model enterocytes, the most abundant epithelial cell type in the intestine. Various methodologies determine chemical permeability through these cells. For example, a recently developed in vitro/in silico hybrid model, termed gut-on-a-chip, uses two fluidic channels separated by a Caco-2 monolayer, and is engineered with microcircuitry to detect absorption of substances (Kim \& Ingber, 2013; Kim et al., 2012; Vergeres et al., 2012). Such models may be applicable to NMs. Further, 3D human-based tissue models (such as MatTek's EpiIntestinal) exist that are commercially available and which may also be applicable to NMs.
A disadvantage of Caco-2 cells is that, when grown in monolayer, they lack a mucus layer, allowing easy access to the apical cell membrane. However, despite this, the rate of paracellular transport is typically more limited than in the human intestine, and total transport values for many conventional molecules through Caco- 2 cells are similar to values obtained through human colon and rectum biopsies (Chen et al., 2010; Rubas et al., 1996). The limited paracellular transport will likely not be an issue for NMs since uptake via this pathway is negligible for materials larger than $1 \mathrm{~nm}$ in the healthy GI tract (Frohlich, 2012). Interlaboratory reproducibility with this model rests in careful attention to culture conditions, such as cell passage number, seeding density and length of time in culture (Natoli et al., 2012). In addition, Caco-2 cells have been demonstrated to produce mucus when grown in more humanrelevant three-dimensional (3D) environments (Kim \& Ingber, 2013). The uptake of food-relevant NMs into cells and transport to the basolateral chamber has been tested with several epithelial cell types.

Caco-2 cells confirmed intestinal absorption of well characterized hemin-coupled iron (III)-hydroxide NPs and of chitosan coated, iron loaded solid lipid NPs, as possible alternatives to oral ferrous salt supplements in iron mineral deficiency (Jahn et al., 2011; Zariwala et al., 2013). The permeability of $40 \mathrm{~nm}$ titanium dioxide NMs was also determined with Caco-2 cells using a dual chamber approach (Koeneman et al., 2010). The average diameter of the NMs in the donor medium was greater than $500 \mathrm{~nm}$, indicating agglomeration. In general, the mass of larger NMs can increase the rate of settling and so the exposure dose to the cells becomes not only the concentration of particles administered, but also is a factor of how much of the total mass in that volume sediments (Cohen et al., 2013; Teeguarden et al., 2007). This might not hold true for agglomerates, of which the effective density can be smaller than their dispersed density (DeLoid et al., 2014). In any model, it is challenging to distinguish binding to the cell surface, which would slow transit time along the GI tract, from uptake into the cell. Koeneman et al. (2010) used scanning confocal microscopy to visualize the titanium dioxide inside the cells, demonstrating absorption by transcellular transcytosis. 
Table 3. In vitro cell culture models that simulate the gastrointestinal tract epithelium, are commonly used to assess the absorption of conventional chemicals, and could be relevant for the assessment of NMs.

\begin{tabular}{|c|c|c|c|c|}
\hline Model & $\begin{array}{c}\text { Species and tissue of } \\
\text { origin }\end{array}$ & $\begin{array}{c}\text { Characteristics and applica- } \\
\text { tions for conventional } \\
\text { chemicals }\end{array}$ & Limitations & $\begin{array}{c}\text { References on } \\
\text { conventional uses }\end{array}$ \\
\hline TR146 cells & $\begin{array}{l}\text { Human buccal } \\
\text { carcinoma }\end{array}$ & $\begin{array}{l}\text { Epithelial origin; forms a } \\
\text { multi-layered squamous } \\
\text { tissue in culture; a model of } \\
\text { chemical permeability } \\
\text { through the buccal } \\
\text { epithelium }\end{array}$ & $\begin{array}{l}\text { Transport mechanisms } \\
\text { require further } \\
\text { characterization }\end{array}$ & Teubl et al. (2013) \\
\hline $\begin{array}{l}\text { 2/4/A1 cells, IEC- } 6 \text { cells, or } \\
\text { IEC-18 cells }\end{array}$ & $\begin{array}{l}\text { Rat intestinal epi- } \\
\text { thelial cells }\end{array}$ & $\begin{array}{l}\text { Good predictors of paracellular } \\
\text { permeability and passive } \\
\text { transport in the human } \\
\text { duodenum }\end{array}$ & $\begin{array}{l}\text { Lack several active trans- } \\
\text { porters and efflux sys- } \\
\text { tems; a poor model of } \\
\text { active transport }\end{array}$ & $\begin{array}{l}\text { Thomas \& Oates (2002), } \\
\text { Versantvoort et al. (2002), } \\
\text { Tavelin et al. (2003) }\end{array}$ \\
\hline Caco-2 with HT29 cells & $\begin{array}{l}\text { Human colorectal } \\
\text { carcinoma cell } \\
\text { lines }\end{array}$ & $\begin{array}{l}\text { Co-culture incorporates a } \\
\text { mucus layer on the entero- } \\
\text { cytes and enhances para- } \\
\text { cellular permeability }\end{array}$ & $\begin{array}{l}\text { The availability of different } \\
\text { cell sub-clones results in } \\
\text { interlaboratory } \\
\text { variability }\end{array}$ & $\begin{array}{l}\text { Walter et al. (1996), } \\
\text { Chen et al. (2010) }\end{array}$ \\
\hline $\begin{array}{l}\text { Caco-2 with Raji B cells, or } \\
\text { Caco- } 2 \text { with } \\
\text { Peyer's patch lymphocytes }\end{array}$ & $\begin{array}{l}\text { Human colorectal } \\
\text { carcinoma cells in } \\
\text { combination with } \\
\text { human Burkitt's } \\
\text { lymphoma cells } \\
\text { or murine Peyer's } \\
\text { patch } \\
\text { lymphocytes }\end{array}$ & $\begin{array}{l}\text { Co-culture induces a fraction of } \\
\text { the Caco- } 2 \text { cells to develop } \\
\text { the morphology of Peyer's } \\
\text { patch epithelial microfold } \\
\text { cells, including few micro- } \\
\text { villi and a soft mucus layer }\end{array}$ & $\begin{array}{l}\text { Variations in primary } \\
\text { lymphocyte preparations } \\
\text { may influence co-culture } \\
\text { characteristics; quantita- } \\
\text { tive correlation to human } \\
\text { uptake not fully } \\
\text { understood }\end{array}$ & $\begin{array}{l}\text { Tyrer et al. (2002), } \\
\quad \text { des Rieux et al. (2007) }\end{array}$ \\
\hline
\end{tabular}

Inductively coupled-plasma mass spectrometry detected microgram quantities of titanium atoms in the basolateral compartment, representing $14 \%$ of the administered material at the $100 \mu \mathrm{g} / \mathrm{mL}$ dose, and $2 \%$ of the administered material at the $1000 \mu \mathrm{g} / \mathrm{mL}$ dose. Approaches should be developed to factor total surface area of the cell monolayer into quantitative determinations such as this. The lower percentage permeability at the high dose may have indicated saturation of cellular absorption mechanisms, but was more likely related to limited permeation through the culture apparatus; as the percentage of titanium that gained access to the basolateral compartment was low even in the absence of cells. While the data demonstrated total absorption of titanium, it did not distinguish between intact NPs and ions in the basolateral fluid. Again, total surface area of the cell monolayer must be indicated to allow validation by comparison with the in vivo surface area of the GI epithelium and total absorption. The demonstration of interlaboratory reproducibility can also aid in standardization. Fisichella et al. (2012a) also used Caco-2 cells in combination with simulated gastric digestion to study the permeability of titanium dioxide NMs consisting of a $10 \mathrm{~nm}$ wide and $50 \mathrm{~nm}$ long rutile core, surrounded by a thin aluminium hydroxide layer, and surface treated with polydimethylsiloxane polymer. Simulated gastric digestion of the NMs in acidic medium removed the polydimethylsiloxane coating, and the product agglomerated to between $720-1350 \mathrm{~nm}$ upon subsequent incubation in cell culture medium. Following 72-h exposure of the Caco- 2 cells, microscopy visualized the agglomerates as tiny spots on the outer surface of the plasma membrane. However, no particles could be seen inside the cells. This difference from the previous study may have been related to the differences in the physico-chemical properties of the NMs (Fisichella et al. $2012 b$ ). The discrepancy highlights the need for the characterization of the NMs, both pristine to know what is being tested and in the model systems to understand the fate and stability in the exposure medium and cellular permeability of each type of NM. 
Next to monocultures, in vitro cell co-culture systems integrate several cell types, thus more adequately resembling the complex anatomy of the GI tract epithelium (Table 3). They model different pathways and mechanisms of chemical and NM permeability. The co-culture models most relevant to NM absorption pathways are discussed below.

HT29 cells secrete mucus and provide a useful model of the adhesive and barrier properties of the GI mucus layer. However, monoculture does not fully reflect the human intestinal epithelium, where goblet cells represent $10-25 \%$ of the cells. This discrepancy can be overcome by co-culturing HT29 cells with Caco-2 cells. Chemical permeability coefficients that correlate with the in vivo situation have been obtained using optimized culture media, cell ratios, culture times and seeding densities (Walter et al., 1996). Several NPs have been tested in this model. For example, iron oxide NPs coated with oleic acid were not transported at a detectable level into or through a Caco-2/HT29 monolayer, despite the $10 \mathrm{~nm}$ diameter of the primary particles (Kenzaoui et al., 2012). However, solid-lipid NPs of approximately $200 \mathrm{~nm}$ permeated the mucus and were absorbed by endocytosis (Yuan et al., 2013). Agglomeration or differences in surface charge and chemistry of the NMs in the media could be a factor in the differential permeability.

In the intestine, microfold (M) cells are localized in the epithelium of Peyer's patch and lymphoid nodules, and are responsible for sampling antigens from the lumen. They are a primary route of particulate matter uptake. Thus, $\mathrm{M}$ cell models are important in the mechanistic investigation of particulate absorption (Shahbazi \& Santos, 2013). Since the percentage of M cells in the epithelial barrier is low, co-culture models facilitate controlled studies. Caco- 2 cells can be co-cultured with either Raji B lymphoma cells or freshly isolated murine Peyer's patch lymphocytes in order to induce the differentiation of a fraction of the Caco-2 cells to an M cell phenotype. The Caco-2 and Raji B lymphoma co-culture dual chamber model characterized the permeability of silver NPs of 20,34, 61 and $113 \mathrm{~nm}$ diameters (Bouwmeester et al., 2011b). Before administration, the suspensions of silver NPs had very low levels of silver ions. However, 24-h incubation in the cell culture medium alone released approximately 5-20\% of the silver content to an ionic form. Thus, conventional silver ions were used as a control treatment. Following NP exposure of the cells, approximately $0.5 \%$ of the silver content from the NPs had translocated from the apical to the basolateral chamber. There was a similar translocation rate when pure silver ions were applied, suggesting that the ions released from the NPs likely contributed to the majority of the translocated material. This observation is similar to that described above following in vivo exposure of rats. This study also highlights the importance of dissolution testing and ionic controls for metals, when possible. The Caco-2 with Peyer's patch lymphocyte coculture model was similarly used to demonstrate $\mathrm{M}$ cell uptake of fluorescent chitosan - deoxyribonucleic acid (DNA) NMs of 50100, 200 and 400-500 nm (Kadiyala et al., 2010). The NMs did not agglomerate during incubation in the cell culture medium, and following $30 \mathrm{~min}$ of cell exposure, fluorescence from the NMs was quantified in the basolateral chamber by flow cytometry, demonstrating that the $50-100 \mathrm{~nm}$ particles had the highest permeability. The percentage of particles that permeated was 5-fold greater through this co-culture $\mathrm{M}$ cell model than through a Caco-2 enterocyte monoculture. Microscopy visualized the fluorescence in the cells, confirming the uptake and transcellular transcytosis of the NMs.

Recently, in vitro 3D cell culture models are emerging that more accurately mimic the structure of the GI mucosa in vivo. For example, buccal TR146 or intestinal Caco- 2 cells can be grown on a 3D collagen scaffold and overlaid with GI mucus and fluids
(Moharamzadeh et al., 2008; Pusch et al., 2011; Yadev et al., 2011; Yu et al., 2012). Whereas the collagen scaffold in those examples can be a limiting barrier for rapidly transported substances, more permeable synthetic membranes can be incorporated in 3D human tissue models (Giovino et al., 2013). Further evaluation and comparison to ex vivo tissue and animal studies, followed by standardization of these novel models will clarify their applicability and accuracy for the prediction of particle uptake rate in humans.

Interest in in vitro cell lines is increasing for the toxico-kinetic analysis of NMs due to their potential for high-throughput, costeffective and good predictability of permeability potential. An additional advantage is the ability to use cell lines that are derived from humans. There are several limitations and possible solutions. Simple cell culture systems using established cell lines do not incorporate factors such as age and sex, and they lack systemic circulation pathways such as the enterohepatic secretion of absorbed materials back into the GI lumen. Emerging approaches to account for different genotypes could possibly be developed, such as the use of induced pluripotent stem cells (Gracz et al., 2013). The InLiveTox project (http://www.inlivetox.eu/) has developed a multi-tissue fluidic model that allows flow above and below a $\mathrm{Caco} 2$ differentiated confluent layer, with the basolateral flow linking to endothelial (HUVEC) and hepatocyte (C3A) culture. Further validation of this model is required to assess its usefulness for NM compared to simple in vitro models and animals. The same approach could be used to link more tissues to better reflect pathways such as enterohepatic circulation.

Another limitation of simpler in vitro systems is that standard culture media do not contain GI lumen factors. More physiologically relevant culture fluids can be used to reflect the fasted and fed states (Patel et al., 2006). Like with any model system, the suspension of NMs in aqueous administration fluids can be problematic (Bihari et al., 2008). If dispersion agents are used in the vehicle to solve this problem, effects on the integrity of the cells and the function of transporters must be ruled out by including the agents in control wells (Buckley et al., 2012). Nonetheless, in vitro cellular models have many unique advantages in the mechanistic analysis of epithelial permeability. The limitations can often be overcome by combining the data from more than one in vitro assay. With the rapidly generated data, mathematical approaches can be used to approximately equate the values to human in situ transcellular permeability (Avdeef \& Tam, 2010; Pelkonen et al., 2001). Further research is required to confirm the accuracy of these equation approaches to NM permeability. If in vitro systems are to be used to reflect NM bioavailability in humans, it is important to be able to characterize not only permeability, but also digestion in GI fluids.

\section{In vitro non-cellular fluid models}

Digestion is a complex process involving physical, chemical, enzymatic and microbial degradation of food as it travels through the buccal cavity, stomach, small intestine and large intestine. Various factors in the lumen influence digestion including ionic strength, $\mathrm{pH}$, digestive enzymes, bile, microbiota, transit time, hydrodynamics and the composition of the food matrix (Brandon et al., 2006). Fluid models that simulate the human GI tract can provide useful ways of evaluating certain aspects of NM digestion including bioaccessibility, stability, dissolution and aggregation (Cockburn et al., 2012). Available models originate from pharmaceutical and food safety research (Table 4). Equipment such as the US Pharmacopeia (USP) I/II dissolution apparatus and basket stirred flask is routinely used to assess the dissolution characteristics of drug substance and dosage forms 
Table 4. In vitro non-cellular fluid models that simulate the gastrointestinal tract, are commonly used to assess the digestion and absorption of conventional chemicals, and could be relevant to the assessment of NMs.

\begin{tabular}{|c|c|c|c|}
\hline Model & $\begin{array}{l}\text { Characteristics and applications } \\
\text { for conventional chemicals }\end{array}$ & Limitations & $\begin{array}{l}\text { References on } \\
\text { conventional uses }\end{array}$ \\
\hline Static digestion models & $\begin{array}{l}\text { Synthetic fluids simulate the enzymatic and chem- } \\
\text { ical digestive conditions in the various compart- } \\
\text { ments of the gastrointestinal tract }\end{array}$ & $\begin{array}{l}\text { Lack the mechanical forces that } \\
\text { contribute to digestion in vivo; } \\
\text { metabolites accumulate and can } \\
\text { interfere with digestion }\end{array}$ & $\begin{array}{l}\text { Versantvoort et al. (2005), } \\
\text { Guhmann et al. (2013) }\end{array}$ \\
\hline Dynamic digestion models & $\begin{array}{l}\text { Synthetic digestive fluids are mixed and propelled } \\
\text { by mechanical forces similar to those encountered } \\
\text { in vivo; bioaccessibility and digestion are mod- } \\
\text { eled for the various compartments of the gastro- } \\
\text { intestinal tract }\end{array}$ & $\begin{array}{l}\text { Specialized equipment required to } \\
\text { generate the physical forces }\end{array}$ & $\begin{array}{l}\text { Minekus et al. (1999), } \\
\text { McAllister (2010) }\end{array}$ \\
\hline Natural and synthetic mucus & $\begin{array}{l}\text { Isolated gastrointestinal mucus incubated in vitro; } \\
\text { models mucoadhesion and permeation through } \\
\text { the mucus }\end{array}$ & $\begin{array}{l}\text { Variations in mucus source and } \\
\text { preparation can influence } \\
\text { characteristics }\end{array}$ & Crater \& Carrier (2010) \\
\hline $\begin{array}{l}\text { Artificial membrane } \\
\text { permeability assays }\end{array}$ & $\begin{array}{l}\text { Non-cellular synthesized membrane on a filter } \\
\text { support models the cell membrane; lipid com- } \\
\text { position can be specified; passive transcellular } \\
\text { permeability is modeled; both hydrophilic and } \\
\text { hydrophobic compounds can be applied }\end{array}$ & $\begin{array}{l}\text { Membrane lacks pores and trans- } \\
\text { porter proteins; does not model } \\
\text { active transport or paracellular } \\
\text { permeability }\end{array}$ & Reis et al. (2010) \\
\hline
\end{tabular}

(McAllister, 2010). Most dissolution models are mixed with an impellor, a magnetic stirrer or a shaker. They mimic the chemical and enzymatic conditions in the human GI tract. However, many do not accurately mimic the complex physical forces that are an important factor in the disintegration of food particles in vivo (Minekus et al., 1999). More sophisticated models recreate the physical environments encountered in the GI tract.

\section{In vitro fluid systems that mimic the lumen of the buccal cavity}

In vivo, the composition of salivary fluid changes in response to a number of stimuli (Yan et al., 2010). Despite this, most simulated salivary fluid experiments use set concentrations of salts, amylase and $\mathrm{pH}$. Since changes in ionic strength and $\mathrm{pH}$ may influence engineered NM stability and agglomeration, it may be more ideal to use several fluids with different osmotic, amylase and $\mathrm{pH}$ values (Guhmann et al., 2013). Moreover, the chewing and swallowing forces encountered in vivo can be modeled using devices with mobile parts, that faithfully reproduce shear, compression and tongue forces (Salles et al., 2007). Further research is required to standardize these models for the application of NMs.

\section{In vitro fluid systems that mimic the lumen of the stomach}

Conditions in the gastric environment, such as $\mathrm{pH}$, enzyme concentration, water content, temperature, pressure, microbial load and emptying rate are continually changing as food is ingested (Minekus et al., 1999). Static in vitro digestion assays using simulated gastric fluids have been well validated to approximate these conditions, for example for the assessment of novel protein stability (Thomas et al., 2004). This type of assay has also been used to determine how gastric conditions impact the behavior of NMs. Silver NPs in simulated gastric fluid agglomerated significantly and released ionic silver from their surface that re-precipitated and coated the agglomerates as insoluble silver chloride (Mwilu et al., 2013). Interestingly, the digestion of pure silver ions also resulted in the de novo formation of silver chloride agglomerates ranging in size from 1 micron to greater than 10 microns, with $50 \mathrm{~nm}$ particles visible on the surface by electron microscopy energy dispersive X-ray spectroscopy. Thus, the precipitation of silver chloride agglomerates was not a phenomenon specific to NMs. However, it was not a characteristic of bulk materials, as conventional silver particles of
1.6-2.6 microns did not significantly dissolve (Rogers et al., 2012). Zinc oxide NPs readily dissolved under gastric conditions (McCracken et al., 2013). Clearly, static in vitro digestion assays using simulated gastric fluids could be used to distinguish a variety of the possible outcomes for NMs.

Several dynamic gastric simulators reproducibly recreate the complex physical mixing and emptying conditions at work in the human stomach (Kong \& Singh, 2010; Wickham et al., 2009). Various food matrices can be applied to determine their influence on the retention, release and breakdown of food particles (Kong \& Singh, 2008; Kong et al., 2011). For example, a dynamic model provided a more accurate simulation of the digestion of a selfemulsifying drug delivery system in terms of droplet size than the conventional USP II dissolution apparatus (Mercuri et al., 2011). However, more studies are required to determine the utility of these systems for the evaluation of the behavior of NMs in food.

\section{In vitro fluid systems that mimic the lumen of the stomach and small intestine}

Static digestion can sequentially simulate the buccal cavity, stomach and small intestine using ionic compositions, digestive enzyme concentrations and $\mathrm{pH}$ profiles close to human physiology (Versantvoort et al., 2005). The digestion of macronutrients has been validated with these models (Kopf-Bolanz et al., 2012), and the models have been applied to study the digestion of NMs by coupling the output material with robust analytical methods appropriate for complex matrices. For example, the fate of silver NMs was evaluated (Bohmert et al., 2013; Walczak et al., 2013). It appears that the presence of proteins and other food components has a crucial impact on the particle size kinetics during the different phases of digestion. In the absence of proteins, $60 \mathrm{~nm}$ silver NMs completely dissolved under stomach conditions, whereas in the presence of proteins they agglomerated to clusters composed of silver NMs and chlorine, as reviewed in another example above, and then disintegrated back into single silver NMs at the intestinal stage of digestion (Walczak et al., 2013). A comparable agglomeration and disintegration phenomenon was observed for silicon dioxide NPs (Peters et al., 2012), whereas $115 \mathrm{~nm}$ aggregates of $21 \mathrm{~nm}$ titanium dioxide NPs maintained a constant size in all of the fluids (McCracken et al., 2013). Simulated intestinal digestion of pure silver ions, again resulted in de novo formation of $20-30 \mathrm{~nm}$ NPs composed of silver, sulfur 
and chlorine (Walczak et al., 2013). These data have allowed consideration that existing health effects data on silver ion exposure may be useful for extrapolation in the risk assessment of silver NPs (Bachler et al., 2013). Hydrophobic solid lipid particles with a $200 \mathrm{~nm}$ diameter agglomerated to approximately $500 \mathrm{~nm}$ during incubation in simulated intestinal fluid, whereas particles coated with poly(ethylene glycol)-stearic acid had limited aggregation (Yuan et al., 2013). Simulated GI fluids provide not only a means of assessing the degree of particle degradation and aggregation, but also of leakage of any fluorescent labels that had been incorporated into the particles (Llabot et al., 2011). Data on NM stability and label release are very useful in the design of subsequent in vitro cell culture studies. The $\mathrm{pH}$ and composition of simulated intestinal fluids are fairly similar to standard cell culture media, and the products of sequential digestion can either be directly applied to a permeability model or replicated in cell culture media (McCracken et al., 2013).

Again, physiological forces are important to consider in in vitro fluid digestion models, for which applicable models are available. TIM-1 is a dynamic in vitro model of the stomach and small intestine that simulates human digestive and physiological processes including appropriate $\mathrm{pH}$, gastric lipase, pepsin and hydrochloric acid, small intestinal pancreatic juice, bile and sodium bicarbonate, peristaltic mixing and transit, temperature and removal of the products of digestion (Minekus et al., 1999). The jejunum and ileum compartments include a semi-permeable dialysis membrane that removes water and the dissolved small molecule products of digestion, allowing quantification of the bioaccessible fraction released from the food matrix (Van de Wiele et al., 2007). The peristaltic mixing and fluid transfer in TIM-1 allowed more accurate prediction of drug dissolution in healthy human volunteers than the USP II and USP IV models (Souliman et al., 2007). For conventional drug and nutritional compounds, TIM-1 has been extensively used to characterize their bioaccessibility from food and beverage product matrices, expressed as a percentage intake, under various physiological conditions and transit times along the GI tract (Blanquet et al., 2004). The profiles are highly consistent with preclinical jejunal data in both fasted and fed states (Souliman et al., 2006). However, the use of a dialysis membrane to provide an absorptive surface does not model active cellular transport. To incorporate this function, it is possible to further analyze the digested fractions, after ultracentrifugation, filtration and dilution, and with a Caco-2 cell permeability assay (Deat et al., 2009). This model could be very relevant for the assessment of both the bioaccessibility and digestion of food-relevant NMs.

\section{In vitro fluid systems that mimic the lumen of the large intestine}

A notable characteristic of the large intestine lumen is the high concentration of microbes. The simplest and most frequently used in vitro models of the human large intestine are static batch fermentations (Ghoddusi et al., 2007). These cultures of intestinal or fecal microbial strains are far from physiological. They suffer from confounding factors such as the accumulation of metabolites, which change $\mathrm{pH}$ and redox potential, inhibit microbial activity and change community structure. However, the highthroughput nature could make batch incubations valuable as an initial screening assay for NMs.

Continuous dynamic models of the large intestine allow more in-depth study of the effect of the gut microbiota on selected food molecules. Several models have been used to date (Cinquin et al., 2004; Macfarlane et al., 1998; Makivuokko et al., 2005; Minekus et al., 1999; Molly et al., 1993). The medium contains factors such as nutrients, resistant starch, vitamins, minerals, bile and pancreatic enzymes, reflecting in vivo conditions. TIM-2, for example, is a dynamic model of the colon that is based on the same technology as TIM-1, described above (Minekus et al., 1999). It is inoculated with a high-density fecal microflora and incorporates peristaltic movement and mixing forces. A dialysis membrane allows removal of microbial metabolites, preventing the inhibition of the fermentation assay. Additional studies with systems such as these can determine the fate of NMs during fermentation in the colon.

Various in vitro non-cellular digestion systems allow highthroughput mechanistic screening of the bioaccessibility, dissolution, aggregation and digestion of NMs in solid, semi-solid and liquid food matrices that reflect fed and fasted states. Clearly, this analysis is possible only when sound analytical methods are available. Several other non-cellular in vitro models similarly require enhanced analytical techniques to ensure their usefulness with NM.

\section{In vitro fluid models mimicking mисus}

The mucus layer represents the first barrier a chemical has to cross in the uptake process. Isolated mucus allows for rapid and convenient analysis of particle adhesion to, or diffusion through, this layer (Table 4). For example, fluorescent cationic chitosan NPs diffused more rapidly through isolated porcine intestinal mucus than mucoadhesive thiol-conjugated particles (Dunnhaupt et al., 2011). While adhesion in vivo can slow the transit toward fecal excretion and thereby increase residence time, it can prevent diffusion through the mucus and prevent absorption by the underlying epithelium. Isolated mucus models in general, and in use with NM, require further investigation, validation and then standardization.

\section{In vitro fluid artificial membrane models}

Models such as the parallel artificial membrane permeability assay analyze the passive permeability of a substance from a donor compartment, through a lipid-infused artificial membrane on a filter support, into an acceptor compartment (Table 4). $\mathrm{pH}$ can affect the surface charge of administered NMs, and can be specified to reflect the properties the NMs would display in the various compartments of the GI tract (Reis et al., 2010). Artificial membrane models could offer high-throughput screening of passive transcellular permeability. Active transport mechanisms would have to be addressed with other systems.

Overall, several categories of in vitro models are used for the assessment of conventional food and drug chemicals and, when standardized, have shown good in vitro to in vivo correlation. These high-throughput systems show promise for NM assessment (Nel et al., 2013). There is a need to further adapt and standardize the available models and the corresponding analytical methods to allow quantification of the digestive fate of engineered NMs (Misra et al., 2012). Furthermore, over time there is a need to streamline the choice of models required to reliably predict NM uptake across the gastrointestinal barrier, as it will be impossible to test all NM in all models (Stone et al., 2014).

\section{In silico computational models}

In silico programs driven by complex computational algorithms are designed to predict how novel substances will behave in humans. Table 5 summarizes relevant in silico models of the GI tract.

When existing solubility, permeability and clearance data for a chemical is available from in vivo animal, ex vivo or in vitro models, in silico physiologically based toxico-kinetics programs can be constructed to extrapolate bioavailability in humans (Paixao et al., 2012). Some data for a very limited number of NM 
Table 5. In silico computational models that simulate the gastrointestinal tract, are increasingly used to assess the dissolution and absorption of conventional chemicals, and could be relevant to the assessment of NMs.

\begin{tabular}{|c|c|c|c|}
\hline Model & Capabilities for conventional chemicals & Limitations & $\begin{array}{l}\text { References on } \\
\text { conventional uses }\end{array}$ \\
\hline $\begin{array}{l}\text { Compartmental absorp- } \\
\text { tion and transit }\end{array}$ & $\begin{array}{l}\text { The dissolution and bioavailability of } \\
\text { chemicals in different compartments of } \\
\text { the human gastrointestinal tract is } \\
\text { modeled based on inputted solubility } \\
\text { and permeability data on that chemical } \\
\text { from in vivo, ex vivo or in vitro studies; } \\
\text { can incorporate food effects and } \\
\text { physiological inter-individual } \\
\text { variability }\end{array}$ & $\begin{array}{l}\text { Uses generalized mathematical } \\
\text { models; prediction of intrinsic } \\
\text { solubility is a challenge }\end{array}$ & $\begin{array}{l}\text { Yu \& Amidon (1999), } \\
\text { Bolger et al. (2009), } \\
\text { Jamei et al. (2009), } \\
\text { Sugano (2009), } \\
\text { Sinha et al. (2012) }\end{array}$ \\
\hline $\begin{array}{l}\text { Statistical machine } \\
\text { learning and } \\
\text { Quantitative } \\
\text { Structure Property } \\
\text { Relationship }\end{array}$ & $\begin{array}{l}\text { Prediction of human intestinal chemical } \\
\text { permeability or bioavailability, based } \\
\text { on the observed or calculated physico- } \\
\text { chemical properties of the molecule; } \\
\text { trained with existing permeability data } \\
\text { from similar molecules in the human } \\
\text { intestine or in Caco- } 2 \text { cells }\end{array}$ & $\begin{array}{l}\text { Molecular descriptor selection is } \\
\text { algorithm- and descriptor soft- } \\
\text { ware package- dependent, lead- } \\
\text { ing to variability in prediction } \\
\text { results among methods; training } \\
\text { data sets limit the applicability } \\
\text { domain; relies on correlations } \\
\text { with property values only, not } \\
\text { on structural features }\end{array}$ & $\begin{array}{l}\text { Linnankoski et al. (2008), } \\
\text { Ahmed \& Ramakrishnan (2012) }\end{array}$ \\
\hline
\end{tabular}

is available, but more is required for a wider range of NM differing in their physicochemical properties. Some compartmental programs also model the relationship between an external dietary dose and internal organ, blood and excretion concentrations over time in animals or humans. Such a model has been developed for silver NMs, for example Bachler et al. (2013). The models are dependent upon the nature and quality of the data used to train and validate the software, and specialized expertise is required to generate and interpret the data. The predictive power of compartmental programs is reduced when estimation of the solubility, permeability and clearance values is required.

Sophisticated quantitative structure-activity relationship (QSAR) software can predict chemical dissolution and bioavailability purely by extrapolation from structural similarity with substances for which these activities are known. QSAR programs have similarly been used in toxicology risk assessment to predict the physiological targets and health effects resulting from human exposure to drugs (Choi et al., 2013; Valerio et al., 2013). In silico models are of growing interest for utility in product development and in safety assessments. They can be just as predictive of human drug bioavailability as data generated with in vivo rat, Caco-2 cell, 2/4/A1 cell and artificial membrane models (Linnankoski et al., 2008).

In silico models could be an ideal approach to aid in the primary screening of the dissolution and absorption of engineered NMs (Winkler et al., 2012). However, in order to train the software for the analysis of novel NMs, a larger database of experimental results is required to document the physico-chemical properties and structures of existing NMs, and their corresponding digestion and absorption values. Descriptors that can be characterized to construct QSAR models include two-dimensional attributes of particle size, surface area, ionization potential, zeta potentials and common physico-chemical properties such as lipophilicity and hydrogen bond donor or acceptor strength. In addition, three-dimensional descriptors of shape can be incorporated in several software programs.
In silico models are high-throughput, efficient for use in prioritization, cost-effective and easily shared if built upon public data. This new research area holds promise for the assessment of NM dissolution and absorption, but requires further critical assessment for specific uses. Further testing is needed to learn which descriptors and computational methods are more accurate for the elucidation of the non-linear relationships that NMs likely possess.

Whereas the aforementioned in vivo, ex vivo, in vitro and in silico models are intended to simulate physiological parameters reflective of the majority of the human population, models are also available that reflect the GI tract in states of varied or altered physiology.

\section{Models reflecting inter-individual variability and disease states of the gastrointestinal tract}

The human population has normal inter-individual variability in the function of the GI tract, resulting from genetic and environmental factors (Rappaport, 2012). For example, the transit time and the composition of the digestive fluids, including $\mathrm{pH}$, enzyme levels and microbes, vary considerably in response to factors such as age, diet and health status (Russell et al., 1993). Significant sub-populations of humans also have inflammatory or precancerous lesions, affecting large areas of the GI tract, and modifying the anatomy and permeability (Camilleri et al., 2012). As described below, early studies show that NM digestion, adhesion and absorption may be altered by these factors. Thus, these varied states can be important to consider and model in the assessment of NM uptake in humans.

As there is no need for inter-species extrapolation, tissues excised from human patients provide an ideal system in which to study the effects of NMs in humans. Human tissues can be used to study inter-individual variability and to focus on individuals of a specific gender, ethnicity or disease state. This allows for the accurate study of diseased human tissue as opposed to animal 
tissue in which a disease condition has been artificially induced. For example, healthy and diseased sections of tissue from patients with Crohn's disease, ulcerative colitis and colonic carcinoma have been examined for the presence of nanoparticles (Powell et al., 1996; Schmidt et al., 2013). In addition, intestinal tissues from humans have been used to examine transmucosal penetration of particles to the vascular endothelium (Nwokolo et al., 1992). Pending ethical approval, further studies of human tissue will be useful in better understanding the fate and effect of NMs in the body and for the validation of other model systems.

\section{Models of inter-individual variability}

With in vivo studies, inter-individual variability can be accounted for not only using an appropriate number of replicate animals per treatment group, but also integrating available data from different animal strains, ages, sexes, stages of pregnancy, diets and/or disease states (Paek et al., 2013; Tryndyak et al., 2012). In vitro this can be accomplished with replicate treatment samples, multiple cell lines or digestive conditions and various disease parameters. Often animal and in vitro models of human diseases are generated by artificially inducing similar states in the animals or cells, and thus when used, the relevance of the disease models to the human conditions needs to be referenced. The necessity of NM testing with such variables should depend on the prevalence of the variables in the general human population, literature that points to hypothesized risks and/or benefits to those subpopulations, and the availability of alternative approaches for accounting for inter-individual variability to protect vulnerable populations, such as uncertainty factors (Canady, 2010).

\section{Models of inflammation}

Inflammation associated with a variety of disease states can affect the integrity of the GI mucosal epithelium, from the oral cavity through to the colon, and can lead to maldigestion and malabsorption (Camilleri et al., 2012; Lefebvre et al., 2006; Meresse et al., 2012). Inflammatory bowel disease includes ulcerative colitis and Crohn's disease; it is one of the most common chronic conditions involving inflammation of the intestine. Numerous animal models of these diseases have been developed, with no single model fully reflecting the pathogenesis observed in humans (Mizoguchi, 2012; Neurath, 2012), suggesting a need for research to improve model relevance. Several models of inflamed intestine have been used to assess NM adhesion and absorption. A passive accumulation of fluorescent polystyrene latex beads specifically in inflamed intestinal areas was first observed in the trinitrobenzene sulfonic acid (TNBS)-induced rat colitis model, following oral exposure (Lamprecht et al., 2001). This was observed qualitatively by using microscopy, and was quantitatively determined from fluorescence in tissue homogenates. The adhesion was size dependent, as $100 \mathrm{~nm}$ particles showed higher levels compared to particles 1000 and $10000 \mathrm{~nm}$ in diameter. A significant extent of the adhesion was to mucus, as scraping the mucus from the excised inflamed tissue before analysis significantly reduced the total fluorescence readout. Polystyrene NPs similarly adhered to gastric ulcers induced by acetic acid in mice (Hassani et al., 2009).

Ex vivo exposure systems can also model the binding and uptake of NMs to the inflamed intestine. Colonic mucosa excised from a rat model of dinitrobenzene sulfonic acid (DNBS)-induced colitis demonstrated adhesion of liposomes to the inflamed regions (Jubeh et al., 2004). A similar adhesion and permeability experiment, using ex vivo tissue biopsies from human volunteers with ulcerative colitis, helped to solve a discrepancy between observations in animals and humans. Although in vivo data from various animal studies had shown selective accumulation of fluorescein labeled poly(L-lactide-co-glycolide) NPs on inflamed regions of the GI tract, Schmidt et al. (2013) could not observe this phenomenon using confocal laser endoscopy on ulcerated rectal areas in human patients with Crohn's disease and colitis. Thus, it was hypothesized that the NPs had been absorbed across the weakened epithelial barrier in the patients, rather than remaining adhered. An ex vivo Ussing chamber assay with resected human biopsies showed a high translocation rate of the NPs through the inflamed tissue, confirming the hypothesis. Additional analytical methods have been used to identify the chemical composition of NMs in human biopsies (Powell et al., 1996).

The favorable comparisons between the rat model of DNBSinduced colitis, the excised tissue from such animals and the excised inflamed human tissue suggests that rodents appear to be useful for assessing the impact of gastrointestinal inflammation of uptake of NM. Either more work is required to use animals with an extended array of NMs, or more work is required to compare the human, in vivo or ex vivo models with in vitro models to generate more useful and reliable alternatives to animal testing. Some such examples are provided below.

In vitro cell culture can model an inflammatory state of the GI tract epithelium. For example, Caco-2 or T84 cells can be treated with tumor necrosis factor-alpha and interferon-gamma, or infected with enteropathogenic Escherichia coli, to induce barrier dysfunction (Zolotarevsky et al., 2002). Mannose-grafted polymeric NPs, for example, showed high accumulation on a Caco-2 pro-inflammatory cytokine model (Coco et al., 2013). 3D in vitro cellular models of oral and intestinal inflammation may also prove useful (Frontela-Saseta et al. 2013; Lambros et al., 2011). One such model uses Caco-2 cells co-cultured with primary macrophages and dendritic cells derived from human blood, and then treated with interleukin 1-beta to induce inflammation (Leonard et al., 2010). A fraction of fluorescently labeled $190 \mathrm{~nm}$ liposomal NPs that deposited on the apical surface of these cells translocated to the basolateral side. The penetration was deeper and of a greater quantity in the inflamed model, and the signal was more diffuse, providing a qualitative measure of the breakdown of the liposomes in the tissue (Leonard et al., 2012). Models of inflammation are very relevant for drug development, but the necessity for the kinetic testing of food-relevant NMs requires further consideration.

\section{Models of epithelial malignancies}

In humans, several compartments of the GI tract can be prone to cancer growth. Carcinogenesis is a multistep progression through defined pre-cancerous intermediaries to a cancerous state. Advanced tumors manifest as morphological entities defined to a particular area, and are usually present in small numbers. Premalignant lesions, on the other hand, are usually present as a population covering a large area. They are morphologically welldefined including features such as premalignant lesions in the oral cavity, polyps in the intestine and aberrant crypt foci in the colon (Gupta et al., 2007; Izumo, 2011; Will et al., 2008). Not only can these lesions modify barrier function, but high-dose chemotherapy regimens can also modify the digestive and absorptive function of the GI tract (Rubenstein et al., 2004). Several in vivo rodent models can be induced to develop premalignant lesions and tumors of the buccal cavity, esophagus, stomach, small intestine and colon that are similar to those observed in humans and are amenable to study interactions with dietary components (Chen \& Lin, 2010; Garman et al., 2012; Lai et al., 2010; Raju, 2008; Raju \& Bird, 2003; Tanaka, 2012; Zeineldin \& Neufeld, 2013; Zhang \& Moss, 2012). Such models could be useful for assessing not only the influence of cancer on NM uptake from the 
gut, but also beneficial targeting of ingested pharmaceutical or imaging NMs to gastrointestinal tumors. Although the majority of available cancer models are in vivo, other categories are emerging, such as the in vitro culture of neoplastic buccal cavity keratinocytes (Costea et al., 2005). Again, little or no literature is available to investigate uptake into such models. The absorption of food-relevant NMs through pre-neoplastic lesions of the GI tract is a nascent research field requiring further consideration in toxico-kinetic assessment.

If used, disease models could reflect not only inter-individual variability resulting from specific disease states, but could possibly also be used to generally reflect differences in human digestion and permeability associated with factors such as age and pregnancy. However, such an approach would require validation with NMs, and alternative approaches should also be considered.

\section{Methodological considerations for nanomaterial detection and characterization}

Various models of the mammalian GI tract are used to assess the digestion and absorption of new food additives, drugs, and more recently of NMs. These facets of toxico-kinetic testing often proceed in a stepwise or tiered manner, where the data obtained from each test is evaluated before considering the utility of further testing. High-throughput in vitro and in silico screening models have been increasingly used in certain aspects of risk assessments, and can provide rapid screening data that are mechanistically relevant to human outcomes ( $\mathrm{Nel}$ et al., 2013). Further confirmatory testing can be conducted in more sophisticated in vitro, ex vivo or in vivo systems; however, data obtained from each test should be evaluated before considering the utility of further testing. With several of these model categories, study designs originally developed to assess conventional ionic and bulk compounds have been recently applied to determine the fate of NMs. As more studies emerge, a database of knowledge appears that is aiding in determining which among these models are most useful for the assessment of NM behavior in the human digestive tract. It is generally accepted that conventional assessment approaches are applicable to NMs (Canady, 2010). However, several methodological gaps and analytical challenges remain with regard to the delivery and detection of food-relevant NMs in these systems.

The NMs administered to test models can be either pristine particles, useful for mechanistic studies or less pure with a range of particle sizes, more realistically reflecting the range of particles that might be found in food products. Characterization of the physico-chemical properties of the NMs is essential to verify what is being administered (Bouwmeester et al., 2009). Recommendations have been published on analytical characterization requirements of engineered $\mathrm{NMs}$ as delivered and following incubation in biological matrices (Bouwmeester et al., 2011a). While the parameters can be unique for metal/mineral, lipid and biochemical NMs, key measurands are common for these categories. Surface area and surface charge are useful mechanistic information, when techniques are available to measure them (Lefebvre et al., 2014). Chemical composition and purity of the source NM are essential characteristics. Dose metrics such as the number-based size distribution of primary particles and of agglomerates can be measured in water or buffer with techniques such as single particle - inductively coupled plasma mass spectrometry, dynamic light scattering, or electron microscopy - energy-dispersive X-ray spectroscopy (Walczak et al., 2013). Mass concentration, total volume, and thus total mass added to the chosen food matrix, gavage diluent or culture media is key information. The actual dose encountered by the cells is impacted by the rate of sedimentation of suspended NMs and agglomerates during the exposure time. Mathematical models such as the In Vitro Sedimentation, Diffusion and Dosimetry (ISDD) model can calculate the apparent density of the NMs in the medium and the dose to the cells (Hinderliter et al., 2010; Teeguarden et al., 2007; Watson et al., 2014). Further research is required to demonstrate whether modifying dose according to these methods alters the conclusions made about the relative toxicity of different nanomaterials. In addition, research is required to compare these models to data from animal or human studies. While the models are an excellent idea in principle, they have not yet been widely adopted because of this lack of information.

Following exposure of the selected model, distinguishing nonlabeled lipid and biochemical macromolecule NMs from other biochemicals already present in biological fluids and tissues is challenging. Non-labeled metal NMs can be more easily distinguished if their atomic constituents are not endogenous to the cells. Due to such challenges, labels are often used for detection.

Fluorescence is a common labeling method for the detection of NMs. In vivo, fluorescence detection of administered NMs can include not only post-mortem analysis of tissues, but also noninvasive imaging. For example, multimodal multiphoton optical microscopy imaging in mice can qualitatively localize fluorescent NPs such as chitosan in organs (Garrett et al., 2012). X-ray computed tomography and NIR fluorescent imaging can also detect NPs such as fluorescent silica-coated gold nanorods (Luo et al., 2011). Metallic nanoshells can be visualized inside a tissue in vivo and ex vivo with a photoacoustic molecular probe and optical projection tomography (Rouleau et al., 2013), and nearinfrared similarly detects the biodistribution of gold and zinc oxide NPs deep in tissues (Lee et al., 2012). With cultured cells, the amount of fluorescently coated iron oxide nanomaterials taken up has been detected by flow cytometry (Wang et al., 2012). As described in previous examples, confocal microscope imaging can also detect fluorescent NMs taken up into the cells, although the resolution is limited to $200 \mathrm{~nm}$ (Gaiser et al., 2012). Alternatively, total internal reflection fluorescence (TIRF) imaging can resolve fluorescent proteins and vesicles smaller than $10 \mathrm{~nm}$ at the cell surface (Rickman et al., 2007). However, microscopic methods are often qualitative and so more quantitative approaches are required. As described earlier, quantitative analysis of the fluorescent signal from NPs in homogenized tissues or cells can be quantified against a standard curve (Llabot et al., 2011).

Isotope labeling of NMs is less practical than fluorescence, but allows for a greater sensitivity of detection. In addition, isotope labeling can be coupled with high precision detection techniques such as multiple collector inductively coupled-plasma mass spectrometry, bioimaging by coherent anti Stokes Raman scattering, and electron microscopy with energy dispersive X-ray spectroscopy. For example, these techniques can be used to detect zinc oxide against a natural zinc background (Larner et al., 2012). Positron emission tomography and neutron activation can detect a wide variety of radiolabeled materials in vivo, ex vivo and in vitro (Gibson et al., 2011). Well-established specialized methodologies using radiolabeled materials have been more reluctantly used in recent years, but scientific questions should be answered using the best suited and available technologies.

As described earlier, the elements making up NMs can be detected as an indication of absorption. With tissue biopsies or cells, autometallography enhanced microscopy or elemental analysis of homogenized tissues can allow accurate quantification of metal NPs (Loeschner et al., 2011). However, if extensive homogenization and furnace preparation of the samples is performed, analyses that only detect the elements present will not indicate whether the NPs remained intact. Single particle inductively coupled-plasma mass spectrometry, 
in combination with hydrodynamic chromatography or field flow fractionation separation allows quantitative determination of intact metal NPs in biological media. The lower particle size limit is approximately $10-20 \mathrm{~nm}$, depending on the chemical composition (van der Zande et al., 2012; Walczak et al., 2013). With intact cellular sections, transmission electron microscopy - electron energy loss spectroscopy is also capable of identifying the chemical composition of individual NPs for many compounds. Refinement of these imaging and analytical detection techniques, and correspondingly of GI models, is an active area or research.

Before delivery of a NM to a model, sterilization may be required to reduce confounding effects from microbial and endotoxin contamination; particularly when using an in vitro cellular system (Neun \& Dobrovolskaia, 2011). Irradiation or heat treatment can be used before administration, although the impact on physico-chemical properties would need to be assessed. Microbial contaminants in the NM product might modify gastrointestinal behavior and fate, and thus might be important to remain present in some systems.

Exposure conditions must be described in detail and should reflect those that would be encountered in humans as closely as possible (Bouwmeester et al., 2009; OECD, 2012). As mentioned above, the exposure vehicle may contain solutes, nutrients and/or serum to improve NM dispersibility, provide physiologically relevant conditions and/or maintain cell health. A vehicle control treatment should include all components except the NMs (Figure 1).

Some NMs have the capacity to bind non-specifically to the glass, plastic, collagen or other matrices that make up administration equipment and culture apparatuses, interfering with the dosing (Shahbazi \& Santos, 2013). Mass balance calculation in the fluids following administration to the apparatus alone can detect this phenomenon. When the cells are present, quantification of the sum of the mass in the donor compartment, receiver compartment and the cells can also ensure that changes in concentration are not due to artifactual removal.
If a fraction of the NPs dissolves to ions, the chosen biological model should be tested by exposure to ions alone for comparison (Figure 1). If available, larger bulk particles of the same material are also useful for comparison.

When NMs are detected with an incorporated label, for example, with a fluorescent molecule or a radioisotope, a level of uncertainty is introduced since the label could dissociate and be absorbed alone (Yuan et al., 2007). As mentioned, this can be controlled for by testing the degree of dissociation of the label from the NM in the exposure media or in synthetic gastrointestinal fluids, and by the administration of the label alone to a control group (Figure 1).

For in vivo and in vitro toxico-kinetics studies, it is ideal if a range of $\mathrm{NM}$ concentrations is administered at known or anticipated human exposure levels. These realistic exposure doses can also allow coinciding, preliminary nutrition and toxicology analysis (Johnston et al., 2013; Teeguarden et al., 2007). Toxicity could be a confounding factor if it changes the permeability of the GI epithelium. Generalized changes in permeability can be quantified with compounds that are known to normally be excluded by the epithelium. For in vitro dual chamber systems, the trans-epithelial electrical resistance (TEER) value also provides a measure of cell monolayer integrity. Loss of TEER can indicate either cell death or the opening of tight junctions between the cells. For example, chitosan polymers transiently enhanced the paracellular absorption of co-administered small molecules (Sonaje et al., 2012).

All models use assumptions, and no method is perfectly accurate or precise. Thus, uncertainty factors are often applied to data when used in risk assessment. For example, an interspecies uncertainty factor is used to account for the level of uncertainty when extrapolating data obtained in animals to the human situation (Cao et al., 2006). An inter-individual uncertainty factor is also applied (Canady, 2010; Huizer et al., 2012). The standardization of methods to analytically quantify NM fate in GI fluids and tissues will reduce methodological uncertainties in the risk assessment of these chemicals.
Figure 1. Control treatments for in vivo, ex vivo and in vitro nanomaterial digestion and absorption assays. (A) Background levels of the nanomaterial in the model should be measured in a control well receiving the vehicle components. (B) The controls are compared with the nanomaterial treatment group. (C) If a fraction of the nanomaterial surface dissolved in simulated gastrointestinal fluids, that concentration of ions can be administered alone, to determine if the ions are responsible for any absorption. (D) If the label dissociated from the nanomaterials in simulated gastrointestinal fluids, that concentration of label can be administered alone, to control for false positives from its absorption.

(A)
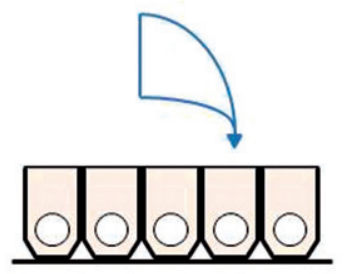

Vehicle
(B)

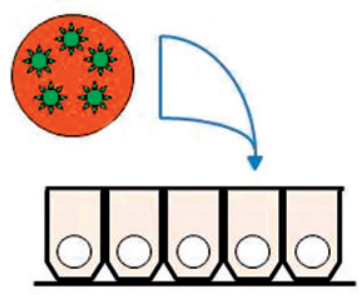

Nanomaterial
(C)

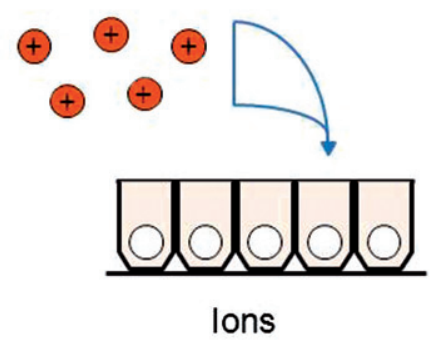

(D)

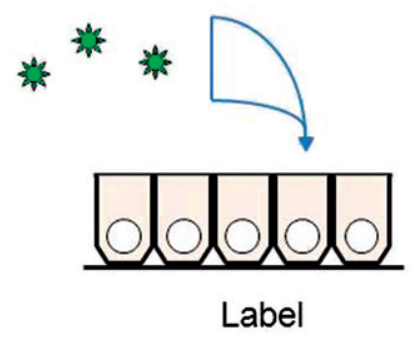




\section{In vivo animal models}

Example: oral toxicokinetic study in an animal; conducted with ethical approval in line with the concepts of replacement, refinement, and reduction

Modelled parameters: digestion, adhesion to mucosal tissue, absorption, and persistence of the nanomaterial in all segments of the gastrointestinal tract

\section{Ex vivo tissue models}

Example: gastrointestinal tract tissues excised from anesthetized test subjects in an ethically approved study, such as an everted intestinal gut sac study

Modelled parameters : nanomaterial adhesion to mucus and permeability through the epithelial cell barrier of the tested gastrointestinal tract segment

\section{In vitro cell culture models}

Examples: (i) epithelial cell line originating from the buccal cavity, (ii) intestinal enterocyte cell line, (iii) co-culture of enterocyte cells with a mucus-producing cell line, and (iv) co-culture of enterocyte cells with leukocytes to generate a microfold cell phenotype.

Modelled parameters : permeability of the naomaterial through the epithelial cells

\section{In vitro non-cellular fluid models}

Examples: (i) fluids simulating the digestive conditions in the lumen of the buccal cavity, stomach, small intestine, and large intestine, (ii) lipid-infused artificial membrane

Modelled parameters : bioaccessibility, digestion, dissolution, aggregation, adhesion to mucus, and passive membrane permeation of the nanomaterial

\section{In silico computational models}

Example: predictive algorithms trained with in vivo, ex vivo or in vitro digestion and absorption data from nanomaterials with similar structural moieties and physico-chemical properties

Modelled parameters : nanomaterial dissolution and absorption

Figure 2. Categories of gastrointestinal tract models that demonstrate potential utility for the assessment of the digestion and absorption of engineered nanomaterials released from food. Specific examples are provided of models that have been used, or could be further developed, to quantify digestion and absorption parameters relevant to nanomaterials. The general parameters that the models could measure are listed.

\section{Conclusions and future research}

Research is accelerating on the application of human-relevant GI tract models to quantify the bioaccessibility, digestion, mucoadhesion, bioavailability and excretion of food-relevant engineered NMs. By integrating the examples provided in this review, we have summarized the current state of the science on models that could be relevant for these quantifications (Figure 2).

There likely will not be a single method that can address all necessary questions, albeit some models are better than others in addressing specific variables. Thus, a combination or battery of models may be required depending on the data gaps addressed. An example approach, for assessing NM uptake in the gastrointestinal tract was proposed earlier in the review. This included that for the testing of novel NMs, a tiered strategy with a thorough physical and chemical characterization in the matrix as dosed, taking into account NM changes over time, followed by alternative testing strategies (in vitro or in silico), would prioritize materials for further testing in vivo. This strategy is not necessarily novel or ground breaking, but instead follows the procedure used for other substances. 
Before such an approach can be taken forward, considerable work is required to develop, validate and standardize such models for use with NMs. In discussing these issues, the previous sections have highlighted some of the gaps in knowledge from this tiered strategic approach, and how they might be addressed. In order to make a useful reference tool to help structure future research priorities in this area, we have generated a table to summarize the identified gaps and the approaches that could be used to address these gaps (Table 6). Additional factors to consider in the selection of models for further development include ease of use, the wide availability of required instrumentation, ethical issues and cost-effectiveness.

In addition to the need to address gaps in, the models available for assessing NM uptake there are also methodological considerations for nanomaterial detection and characterization that need to be addressed. Research is required to further validate and

Table 6. Gaps and proposed research strategies for models of the digestion and absorption of engineered nanomaterials in the gastrointestinal tract.

Identified gap

Overarching strategy required to assess uptake of NMs via the gastrointestinal tract

Require validated and standardized models and analytical tools for the detection of NMs in food, complex media, chyme and feces, as well as within cells and tissues of the GI tract

Require validation and standardization of GI models - general comments

Require assessment of the appropriateness of in vivo models

Need to understand factors affecting mucus penetration by NMs

Require improved alternative models - cell based systems

Simple cell culture systems using established cell lines do not incorporate factors such as age and sex.

Simple cell culture systems using established cell lines lack systemic circulation pathways such as the enterohepatic secretion.

Standard culture media does not contain GI lumen factors

Agglomeration and settling vary according to the physicochemical properties of NMs and this then influences the dose rate to cells.

Require improved alternative models - non-cellular fluid models

\section{Approaches to address gaps}

- A tiered strategy: (i) thorough physical and chemical characterization in the matrix as dosed, taking into account NM changes over time, (ii) high-throughput toxicokinetic approaches such as human-relevant in vitro or in silico systems, (iii) further testing in vivo.

- Assess reliability of analytical digestion and detection for routine use (e.g. Szakal et al., 2014b).

- Radiolabeled materials have been used more reluctantly used in recent years, but these may need to be applied to answer scientific uptake questions.

- Adapt test models used for conventional drugs.

- Assess and modify if necessary the current OECD 2010 guidelines for toxicokinetics studies.

- Assess relevance of administration via gavage versus introduction into food or water.

- Either confirm relevance of existing techniques (e.g. neutron activation, radioactivity or fluorescent tags) or develop improved (or simpler) approaches to better quantify uptake of NM from the gastrointestinal tract into blood over time, and their subsequent biodistribution.

- Extend existing and newly improved techniques to a wider array of NMs with different physicochemical properties.

- Determine differences between humans and rodent models in terms of uptake and how parameters (e.g. food intake) modify uptake.

- Utilize in situ perfusion models in live, anesthetized subjects to assess uptake.

- Assess physicochemical characteristics of NM that influence their interaction with mucus.

- Develop and utilize models to better represent the diversity of cell types in the gastrointestinal mucosa.

- Incorporate permeable synthetic membranes into 3D human tissue models.

- Determine the relationship between NM concentration in the media, internal dose and toxicity in vitro and relate this to the in vivo uptake.

- Evaluate in vitro models compared to ex vivo tissue and animal models, followed by standardization of these novel models to clarify their applicability and accuracy for the prediction of particle uptake rate in humans.

- Combine the data from more than one in vitro assay to address limitations of simple in vitro systems.

- Simultaneously validate analytical tools with human-relevant in vitro or in silico methods.

- Assess the effects of NM agglomeration and sedimentation on ex vivo models such as the gut sac.

- NMs administered to test models can be either pristine particles, useful for mechanistic studies, or manipulated to more realistically reflecting the range of particles that might be found in food products.

- Cell lines with different genotypes could be developed, e.g. via induced pluripotent stem cells.

- Develop and exploit multi-tissue fluidic model that allows flow.

- More physiologically relevant culture fluids can be used to reflect the fasted and fed states.

- Mathematical models such as the In Vitro Sedimentation, Diffusion and Dosimetry (ISDD) model can calculate the apparent density of the NMs in the medium and the dose to the cells (Hinderliter et al., 2010; Teeguarden et al., 2007; Watson et al., 2014).

- Further research is required to demonstrate whether modifying dose according to the ISDD model alters the conclusions made about the relative toxicity of different NMs.

- Research is required to compare the ISDD model to data from animal or human studies.

- Research is required to assess whether mass is the best metric for dose, or whether other options (e.g. surface area or particle number) might be more useful.

- Use fluid models that simulate the human GI tract to evaluate certain aspects of NM digestion including bioaccessibility, stability, dissolution and aggregation.

- Static in vitro digestion assays using simulated gastric fluids could be used to distinguish a variety of the possible outcomes for NMs.

- Dynamic gastric simulators which recreate physical mixing and emptying conditions at work in the human can be applied to determine their influence on the retention, release, and breakdown of food particles and NM, but requires validation for evaluation of the behavior of NMs in food. 
Many non-cellular fluid models do not accurately mimic the complex physical forces that are an important factor in the disintegration of food particles in vivo.

In vitro fluid systems that mimic the lumen of the buccal cavity

Impacts of NM on microflora

Modelling of uptake

There are a lack of disease models relevant for studying inter-individual variability in NM uptake from the gastrointestinal tract
- NMs administered to test models can be either pristine particles, useful for mechanistic studies, or manipulated to more realistically reflecting the range of particles that might be found in food products.

- Chewing and swallowing forces encountered in vivo can be modeled using devices with mobile parts.

- Use several fluids with different osmotic, amylase and $\mathrm{pH}$ values.

- Research is required to standardize in vitro fluid system models that mimic the lumen of the buccal cavity for the application of NMs.

- In vivo assess diversity of microorganisms in faeces over time after NM exposure.

- In vitro assess impact on commensal and pathogenic microorganisms.

- Develop and validate in vitro models of epithelial and microorganism co-culture to investigate how such interactions influence NM uptake.

- Mathematical approaches can be used to approximately equate uptake values to human in situ transcellular permeability.

- Characterize not only permeability, but also digestion in GI fluids.

- Development of models of specific disease states (e.g. inflammatory bowel disease, Crohn's disease and cancer). Examples of such models include:

- In vivo rodent models induced to develop premalignant lesions and tumors of the buccal cavity, esophagus, stomach, small intestine and colon.

- The rat model of dinitrobenzene sulphonic acid-induced colitis.

- Development of models that reflect differences in human digestion and permeability associated with factors such as age and pregnancy.

- Include alternative approaches to represent different physiological and diseases states Examples of such models include:

- The in vitro culture of neoplastic buccal cavity keratinocytes (Costea et al., 2005).

- Caco-2 or T84 cells treated with tumor necrosis factor-alpha and interferon-gamma, or infected with enteropathogenic Escherichia coli, to induce barrier dysfunction (Zolotarevsky et al., 2002).

- Caco-2 cells co-cultured with primary macrophages and dendritic cells derived from human blood, and then treated with interleukin 1-beta to induce inflammation (Leonard et al., 2010).

- Use of ex vivo tissue biopsies from human volunteers with ulcerative colitis.

- Such models would not only identify how disease influences uptake, but could provide beneficial targeting of ingested pharmaceutical or imaging NMs to gastrointestinal disease sites. standardize models and analytical tools for the detection of NMs in food, complex media, chyme and feces, as well as within cells and tissues of the GI tract. These future research areas are being studied by the ILSI NanoRelease Food Additive project (Szakal et al., 2014a).

Such studies will require more work to ensure the reliability of a variety of techniques including analytical digestion and detection. Therefore, while a range of techniques exist to detect NMs in complex matrices and biological specimens, robust and cost effective protocols for routine use are still required. This element of detection, which is essential for estimating exposure, remains a major bottleneck in many risk assessment studies (Stone et al., 2014).

The standardization of GI models and NM detection methods can go hand-in-hand, and method suitability evaluation could include interlaboratory reproducibility experiments with standard food-relevant compounds. A suitability approach could be adapted from those used to test models with conventional drugs (Volpe, 2010). Analytical research needs that have been identified by the NanoRelease Food Additive project include methods to sample, separate, detect and measure inorganic and organic NMs at key time points in the food lifecycle, including during engineering, food preparation, packaging, consumption and GI tract transit (Szakal et al., 2014a).

The final decision regarding what is needed to assess NM uptake for risk assessment may also be influenced by local regulatory requirements. Different jurisdictions may or may not require data on these parameters as part of a safety assessment for the use of novel engineered NMs in food or food contact materials. The categories of models that can be used for such testing varies at the discretion of each jurisdiction.

The development of methodologies for the detection of engineered NMs during digestion and absorption will enhance the capacity to assess the fate of these products in the body, and will facilitate their safe and sustainable development in food applications. Finally, the results from any approach should be interpreted with caution in the risk assessment of NMs proposed for human consumption until there is a body of knowledge confirming the general relevance of the model to humans.

Overall, several categories of in vitro models are used for the assessment of conventional food and drug chemicals and, when standardized, have the potential to show good in vitro to in vivo correlation. There is a need to further adapt and standardize the available models and the corresponding analytical methods to allow quantification of the digestive fate of engineered NMs including uptake across the gastrointestinal barrier.

\section{Acknowledgements}

The authors thank the NanoRelease Food Additive secretariat for their excellent work in coordinating this review, including Richard Canady, Lyubov Tsytsikova, Molly Bloom and Elyse Lee (all of the International Life Sciences Institute Research Foundation, USA). We acknowledge the 
NanoRelease Food Additive Steering Committee, which operates as an independent public-private partnership (http://www.ilsi.org/ ResearchFoundation/RSIA/Pages/FoodAdditiveSteeringCommittee. aspx), for convening the authors of this review, and for developing the initial framing concepts for the paper. The advisory contributions of James Waldman (Ohio State University), Susann Bellman (TNO, Netherlands), Alastair Watson (University of East Anglia), and Jonathan Powell (MRC Human Nutrition Research) are also acknowledged. We thank Bevan Pearce (Health Canada) for assisting with the Pubmed literature searches, and Joel Rotstein and Azam Tayabali (Health Canada) for reviewing the manuscript.

\section{Declaration of interest}

The authors report no conflict of interest. The authors alone are responsible for the content and writing of the paper. In the past, Vicki Stone had received research funding from Unilever. The initial convening Steering Committee phase of the NanoRelease Food Additive project was funded by the Pew Charitable Trusts, the US Food and Drug Administration, Health Canada, ILSI North America, the Coca-Cola Company, the Illinois Institute of Technology's Institute for Food Safety and Health and the ILSI Research Foundation. Substantial in-kind support was provided by the Nanotechnology Industries Association. The content of this publication does not necessarily reflect the views or policies of the US Department of Health and Human Services, nor does mention of trade names, commercial products, or organizations imply endorsement by the US Government. This paper reflects the current thinking and experience of the authors.

\section{References}

Ahmed SS, Ramakrishnan V. 2012. Systems biological approach of molecular descriptors connectivity: optimal descriptors for oral bioavailability prediction. PLoS One 7:e40654.

Alam MA, Al-Jenoobi FI, Al-Mohizea AM. 2012. Everted gut sac model as a tool in pharmaceutical research: limitations and applications. J Pharm Pharmacol 64:326-36.

Alger H, Momcilovic D, Carlander D, Duncan TV. 2014. Methods to evaluate uptake of engineered nanomaterials by the alimentary tract. Compr Rev Food Sci Food Saf 13:705-29.

Avdeef A, Tam KY. 2010. How well can the Caco-2/Madin-Darby canine kidney models predict effective human jejunal permeability? J Med Chem 53:3566-84.

Bachler G, von Goetz N, Hungerbuhler K. 2013. A physiologically based pharmacokinetic model for ionic silver and silver nanoparticles. Int $\mathrm{J}$ Nanomedicine 8:3365-82.

Behrens I, Pena AI, Alonso MJ, Kissel T. 2002. Comparative uptake studies of bioadhesive and non-bioadhesive nanoparticles in human intestinal cell lines and rats: the effect of mucus on particle adsorption and transport. Pharm Res 19:1185-93.

Bihari P, Vippola M, Schultes S, Praetner M, Khandoga AG, Reichel CA, et al. 2008. Optimized dispersion of nanoparticles for biological in vitro and in vivo studies. Part Fibre Toxicol 5:14. doi:10.1186/17438977-5-14.

Blanquet S, Zeijdner E, Beyssac E, Meunier JP, Denis S, Havenaar R, Alric M. 2004. A dynamic artificial gastrointestinal system for studying the behavior of orally administered drug dosage forms under various physiological conditions. Pharm Res 21:585-91.

Bohmert L, Girod M, Hansen U, Maul R, Knappe P, Niemann B, et al. 2013. Analytically monitored digestion of silver nanoparticles and their toxicity for human intestinal cells. Nanotoxicology 8:631-42.

Bolger MB, Lukacova V, Woltosz WS. 2009. Simulations of the nonlinear dose dependence for substrates of influx and efflux transporters in the human intestine. AAPS J 11:353-63.

Bouwmeester H, Dekkers S, Noordam MY, Hagens WI, Bulder AS, de Heer C, et al. 2009. Review of health safety aspects of nanotechnologies in food production. Regul Toxicol Pharmacol 53:52-62.

Bouwmeester H, Lynch I, Marvin HJ, Dawson KA, Berges M, Braguer D, et al. 2011a. Minimal analytical characterization of engineered nanomaterials needed for hazard assessment in biological matrices. Nanotoxicology 5:1-11.

Bouwmeester H, Poortman J, Peters RJ, Wijma E, Kramer E, Makama S, et al. 2011b. Characterization of translocation of silver nanoparticles and effects on whole-genome gene expression using an in vitro intestinal epithelium coculture model. ACS Nano 5:4091-103.

Brandon EF, Oomen AG, Rompelberg CJ, Versantvoort CH, van Engelen JG, Sips AJ. 2006. Consumer product in vitro digestion model: bioaccessibility of contaminants and its application in risk assessment. Regul Toxicol Pharmacol 44:161-71.

Buckley ST, Fischer SM, Fricker G, Brandl M. 2012. In vitro models to evaluate the permeability of poorly soluble drug entities: challenges and perspectives. Eur J Pharm Sci 45:235-50.

Camilleri M, Madsen K, Spiller R, Greenwood-Van Meerveld B, Verne GN. 2012. Intestinal barrier function in health and gastrointestinal disease. Neurogastroenterol Motil 24:503-12.

Canady RA. 2010. The uncertainty of nanotoxicology: report of a society for risk analysis workshop. Risk Anal 30:1663-70.

Cao X, Gibbs ST, Fang L, Miller HA, Landowski CP, Shin HC, et al. 2006. Why is it challenging to predict intestinal drug absorption and oral bioavailability in human using rat model. Pharm Res 23:1675-86.

Card JW, Jonaitis TS, Tafazoli S, Magnuson BA. 2011. An appraisal of the published literature on the safety and toxicity of food-related nanomaterials. Crit Rev Toxicol 41:22-49.

Carreno-Gomez B, Woodley JF, Florence AT. 1999. Studies on the uptake of tomato lectin nanoparticles in everted gut sacs. Int J Pharm 183: $7-11$.

Chen XM, Elisia I, Kitts DD. 2010. Defining conditions for the co-culture of Caco-2 and HT29-MTX cells using Taguchi design. J Pharmacol Toxicol Methods 61:334-42.

Chen YK, Lin LM. 2010. DMBA-induced hamster buccal pouch carcinoma and VX2-induced rabbit cancer as a model for human oral carcinogenesis. Exp Rev Anticancer Ther 10:1485-96.

Choi SS, Kim JS, Valerio Jr LG, Sadrieh N. 2013. In silico modeling to predict drug-induced phospholipidosis. Toxicol Appl Pharmacol 269: 195-204.

Chopra DP, Dombkowski AA, Stemmer PM, Parker GC. 2010. Intestinal epithelial cells in vitro. Stem cells Dev 19:131-42.

Christensen J, El-Gebali S, Natoli M, Sengstag T, Delorenzi M, Bentz S, et al. 2012. Defining new criteria for selection of cell-based intestinal models using publicly available databases. BMC Genomics 13:274.

Cinquin C, Le Blay G, Fliss I, Lacroix C. 2004. Immobilization of infant fecal microbiota and utilization in an in vitro colonic fermentation model. Microb Ecol 48:128-38.

Cockburn A, Bradford R, Buck N, Constable A, Edwards G, Haber B, et al. 2012. Approaches to the safety assessment of engineered nanomaterials (ENM) in food. Food Chem Toxicol 50:2224-42.

Coco R, Plapied L, Pourcelle V, Jerome C, Brayden DJ, Schneider YJ, Preat V. 2013. Drug delivery to inflamed colon by nanoparticles: comparison of different strategies. Int J Pharm 440:3-12.

Cohen J, Deloid G, Pyrgiotakis G, Demokritou P. 2013. Interactions of engineered nanomaterials in physiological media and implications for in vitro dosimetry. Nanotoxicology 7:417-31.

Costea DE, Johannessen AC, Vintermyr OK. 2005. Fibroblast control on epithelial differentiation is gradually lost during in vitro tumor progression. Differentiation 73:134-41.

Crater JS, Carrier RL. 2010. Barrier properties of gastrointestinal mucus to nanoparticle transport. Macromol Biosci 10:1473-83.

Deat E, Blanquet-Diot S, Jarrige JF, Denis S, Beyssac E, Alric M. 2009. Combining the dynamic TNO-gastrointestinal tract system with a Caco-2 cell culture model: application to the assessment of lycopene and alpha-tocopherol bioavailability from a whole food. J Agric Food Chem 57:11314-20.

Dekkers S, Krystek P, Peters RJ, Lankveld DP, Bokkers BG, van HoevenArentzen PH, et al. 2011. Presence and risks of nanosilica in food products. Nanotoxicology 5:393-405.

DeLoid G, Cohen JM, Darrah T, Derk R, Rojanasakl L, Pyrgiotakis G, et al. 2014. Estimating the effective density fo engineered nanomaterials for in vitro dosimetry. Nat Commun 5:3514. doi:10.1038/ ncomms 4514

des Rieux A, Fievez V, Theate I, Mast J, Preat V, Schneider YJ. 2007. An improved in vitro model of human intestinal follicle-associated epithelium to study nanoparticle transport by $\mathrm{m}$ cells. Eur J Pharm Sci 30:380-91.

Donato RP, El-Merhibi A, Gundsambuu B, Mak KY, Formosa ER, Wang $\mathrm{X}$, et al. 2011. Studying permeability in a commonly used epithelial cell line: T84 intestinal epithelial cells. Methods Mol Biol 763:115-37.

Dunnhaupt S, Barthelmes J, Hombach J, Sakloetsakun D, Arkhipova V, Bernkop-Schnurch A. 2011. Distribution of thiolated mucoadhesive nanoparticles on intestinal mucosa. Int J Pharm 408:191-9. 
Fisichella M, Berenguer F, Steinmetz G, Auffan M, Rose J, Prat O. 2012a. Intestinal toxicity evaluation of $\mathrm{TiO}_{2}$ degraded surface-treated nanoparticles: a combined physico-chemical and toxicogenomics approach in Caco-2 cells. Part Fibre Toxicol 9:18.

Fisichella M, Berenguer F, Steinmetz G, Auffan M, Rose J, Prat O. 2012b. Reply to comment on Fisichella et al. (2012), "Intestinal toxicity evaluation of $\mathrm{TiO}_{2}$ degraded surface-treated nanoparticles: a combined physico-chemical and toxicogenomics approach in Caco-2 cells" by Faust et al. Part Fibre Toxicol 9:39. doi:10.1186/1743-8977-9-39.

Frohlich E. 2012. The role of surface charge in cellular uptake and cytotoxicity of medical nanoparticles. Int J Nanomedicine 7:5577-91.

Frontela-Saseta C, Lopez-Nicolas R, Gonzalez-Bermudez CA, MartinezGracia C, Ros-Berruezo G. 2013. Anti-inflammatory properties of fruit juices enriched with pine bark extract in an in vitro model of inflamed human intestinal epithelium: the effect of gastrointestinal digestion. Food Chem Toxicol 53:94-9.

Gaiser BK, Fernandes TF, Jepson MA, Lead JR, Tyler CR, Baalousha M, et al. 2012. Interspecies comparisons on the uptake and toxicity of silver and cerium dioxide nanoparticles. Environ Toxicol Chem 31: 144-54.

Gamboa JM, Leong KW. 2013. In vitro and in vivo models for the study of oral delivery of nanoparticles. Adv Drug Deliv Rev 65:800-10.

Garman KS, Orlando RC, Chen X. 2012. Review: experimental models for Barrett's esophagus and esophageal adenocarcinoma. Am J Physiol Gastrointest Liver Physiol 302:G1231-43.

Garrett NL, Lalatsa A, Uchegbu I, Schatzlein A, Moger J. 2012. Exploring uptake mechanisms of oral nanomedicines using multimodal nonlinear optical microscopy. J Biophoton 5:458-68.

Ghoddusi HB, Grandison MA, Grandison AS, Tuohy KM. 2007. In vitro study on gas generation and prebiotic effects of some carbohydrates and their mixtures. Anaerobe 13:193-9.

Gibson N, Holzwarth U, Abbas K, Simonelli F, Kozempel J, Cydzik I, et al. 2011. Radiolabelling of engineered nanoparticles for in vitro and in vivo tracing applications using cyclotron accelerators. Arch Toxicol 85:751-73

Giovino C, Ayensu I, Tetteh J, Boateng JS. 2013. An integrated buccal delivery system combining chitosan films impregnated with peptide loaded PEG-b-PLA nanoparticles. Colloids Surf B Biointerfaces 112: $9-15$.

Gracz AD, Fuller MK, Wang F, Li L, Stelzner M, Dunn JC, et al. 2013. Brief report: CD24 and CD44 mark human intestinal epithelial cell populations with characteristics of active and facultative stem cells. Stem cells 31:2024-30.

Guhmann M, Thommes M, Gerber F, Pollinger N, Klein S, Breitkreutz J, Weitschies W. 2013. Design of biorelevant test setups for the prediction of diclofenac in vivo features after oral administration. Pharm Res 30: 1483-501.

Gupta AK, Pretlow TP, Schoen RE. 2007. Aberrant crypt foci: ehat we know and what we need to know. Clin Gastroenterol Hepatol 5:526-33.

Hagens WI, Oomen AG, de Jong WH, Cassee FR, Sips AJ. 2007. What do we (need to) know about the kinetic properties of nanoparticles in the body? Regul Toxicol Pharmacol 49:217-29.

Hassani S, Pellequer Y, Lamprecht A. 2009. Selective adhesion of nanoparticles to inflamed tissue in gastric ulcers. Pharm Res 26: 1149-54.

Hinderliter PM, Minard KR, Orr G, Chrisler WB, Thrall BD, Pounds JG, Teeguarden JG. 2010. ISDD: a computational model of particle sedimentation, diffusion and target cell dosimetry for in vitro toxicity studies. Part Fibre Toxicol 7:36. doi:10.1186/1743-8977-7-36.

Huizer D, Oldenkamp R, Ragas AM, van Rooij JG, Huijbregts MA. 2012. Separating uncertainty and physiological variability in human pbpk modelling: the example of 2-propanol and its metabolite acetone. Toxicol Lett 214:154-65.

Izumo T. 2011. Oral premalignant lesions: from the pathological viewpoint. Int J Clin Oncol 16:15-26.

Jahn MR, Shukoor I, Tremel W, Wolfrum U, Kolb U, Nawroth T, Langguth P. 2011. Hemin-coupled iron (iii)-hydroxide nanoparticles show increased uptake in Caco-2 cells. J Pharm Pharmacol 63: 1522-30.

Jamei M, Turner D, Yang J, Neuhoff S, Polak S, Rostami-Hodjegan A, Tucker G. 2009. Population-based mechanistic prediction of oral drug absorption. AAPS J 11:225-37.

Jani PU, McCarthy DE, Florence AT. 1994. Titanium dioxide (rutile) particle uptake from the rat GI tract and translocation to systemic organs after oral administration. Int J Pharm 105:157-68.
Johnston H, Pojana G, Zuin S, Jacobsen NR, Moller P, Loft S, et al. 2013. Engineered nanomaterial risk. Lessons learnt from completed nanotoxicology studies: potential solutions to current and future challenges. Crit Rev Toxicol 43:1-20.

Jubeh TT, Barenholz Y, Rubinstein A. 2004. Differential adhesion of normal and inflamed rat colonic mucosa by charged liposomes. Pharm Res 21:447-53.

Kadiyala I, Loo Y, Roy K, Rice J, Leong KW. 2010. Transport of chitosan-DNA nanoparticles in human intestinal M-cell model versus normal intestinal enterocytes. Eur J Pharm Sci 39:103-9.

Kenzaoui BH, Vila MR, Miquel JM, Cengelli F, Juillerat-Jeanneret L. 2012. Evaluation of uptake and transport of cationic and anionic ultrasmall iron oxide nanoparticles by human colon cells. Int J Nanomedicine 7:1275-86.

Kim HJ, Huh D, Hamilton G, Ingber DE. 2012. Human gut-on-a-chip inhabited by microbial flora that experiences intestinal peristalsis-like motions and flow. Lab on a chip 12:2165-74.

Kim HJ, Ingber DE. 2013. Gut-on-a-chip microenvironment induces human intestinal cells to undergo villus differentiation. Integr Biol (Camb) 5:1130-40

Kim JS, Mitchell S, Kijek P, Tsume Y, Hilfinger J, Amidon GL. 2006. The suitability of an in situ perfusion model for permeability determinations: utility for BCS class I biowaiver requests. Mol Pharm 3:686-94.

Koeneman BA, Zhang Y, Westerhoff P, Chen Y, Crittenden JC, Capco DG. 2010. Toxicity and cellular responses of intestinal cells exposed to titanium dioxide. Cell Biol Toxicol 26:225-38.

Kong F, Oztop MH, Singh RP, McCarthy MJ. 2011. Physical changes in white and brown rice during simulated gastric digestion. J Food Sci 76: E450-7.

Kong F, Singh RP. 2008. A model stomach system to investigate disintegration kinetics of solid foods during gastric digestion. J Food Sci 73:E202-10.

Kong F, Singh RP. 2010. A human gastric simulator (HGS) to study food digestion in human stomach. J Food Sci 75:E627-35.

Kopf-Bolanz KA, Schwander F, Gijs M, Vergeres G, Portmann R, Egger L. 2012. Validation of an in vitro digestive system for studying macronutrient decomposition in humans. J Nutr 142:245-50.

Lai CH, Chang NW, Lin CF, Lin CD, Lin YJ, Wan L, et al. 2010. Proteomics-based identification of haptoglobin as a novel plasma biomarker in oral squamous cell carcinoma. Clin Chim Acta 411: 984-91.

Lambros MP, Parsa C, Mulamalla H, Orlando R, Lau B, Huang Y, et al. 2011. Identifying cell and molecular stress after radiation in a threedimensional (3-D) model of oral mucositis. Biochem Biophys Res Commun 405:102-6.

Lamprecht A, Schafer U, Lehr CM. 2001. Size-dependent bioadhesion of micro- and nanoparticulate carriers to the inflamed colonic mucosa. Pharm Res 18:788-93.

Larner F, Dogra Y, Dybowska A, Fabrega J, Stolpe B, Bridgestock LJ, et al. 2012. Tracing bioavailability of $\mathrm{ZnO}$ nanoparticles using stable isotope labeling. Environ Sci Technol 46:12137-45.

Lee CM, Jeong HJ, Yun KN, Kim DW, Sohn MH, Lee JK, et al. 2012. Optical imaging to trace near infrared fluorescent zinc oxide nanoparticles following oral exposure. Int J Nanomedicine 7:3203-9.

Lefebvre DE, Pearce B, Fine J, Chomyshyn E, Ross N, Halappanavar S, et al. 2014. In vitro enhancement of mouse T helper 2 cell sensitization to ovalbumin allergen by carbon black nanoparticles. Toxicol Sci 138: 322-32.

Lefebvre DE, Powell KL, Strom A, Scott FW. 2006. Dietary proteins as environmental modifiers of type 1 diabetes mellitus. Annu Rev Nutr 26:175-202.

Lennernas H. 2007. Animal data: the contributions of the ussing chamber and perfusion systems to predicting human oral drug delivery in vivo. Adv Drug Deliv Rev 59:1103-20.

Lennernas H, Lee ID, Fagerholm U, Amidon GL. 1997. A residence-time distribution analysis of the hydrodynamics within the intestine in man during a regional single-pass perfusion with Loc-I-Gut: in-vivo permeability estimation. J Pharm Pharmacol 49:682-6.

Leonard F, Ali H, Collnot EM, Crielaard BJ, Lammers T, Storm G, Lehr CM. 2012. Screening of budesonide nanoformulations for treatment of inflammatory bowel disease in an inflamed $3 \mathrm{~d}$ cell-culture model. ALTEX 29:275-85.

Leonard F, Collnot EM, Lehr CM. 2010. A three-dimensional coculture of enterocytes, monocytes and dendritic cells to model inflamed intestinal mucosa in vitro. Mol Pharm 7:2103-19. 
Liebsch M, Grune B, Seiler A, Butzke D, Oelgeschlager M, Pirow R, et al. 2011. Alternatives to animal testing: current status and future perspectives. Arch Toxicol 85:841-58.

Linnankoski J, Ranta VP, Yliperttula M, Urtti A. 2008. Passive oral drug absorption can be predicted more reliably by experimental than computational models - fact or myth. Eur J Pharm Sci 34:129-39.

Llabot JM, Salman H, Millotti G, Bernkop-Schnurch A, Allemandi D, Manuel Irache J. 2011. Bioadhesive properties of poly(anhydride) nanoparticles coated with different molecular weights chitosan. J Microencapsul 28:455-63.

Loeschner K, Hadrup N, Qvortrup K, Larsen A, Gao X, Vogel U, et al. 2011. Distribution of silver in rats following 28 days of repeated oral exposure to silver nanoparticles or silver acetate. Part Fibre Toxicol 8:18. doi:10.1186/1743-8977-8-18.

Luo T, Huang P, Gao G, Shen G, Fu S, Cui D, et al. 2011. Mesoporous silica-coated gold nanorods with embedded indocyanine green for dual mode X-ray CT and NIR fluorescence imaging. Opt Express 19: 17030-9.

Macfarlane GT, Macfarlane S, Gibson GR. 1998. Validation of a threestage compound continuous culture system for investigating the effect of retention time on the ecology and metabolism of bacteria in the human colon. Microb Ecol 35:180-7.

Makivuokko H, Nurmi J, Nurminen P, Stowell J, Rautonen N. 2005. In vitro effects on polydextrose by colonic bacteria and Caco-2 cell cyclooxygenase gene expression. Nutr Cancer 52:94-104.

McAllister M. 2010. Dynamic dissolution: a step closer to predictive dissolution testing? Mol Pharm 7:1374-87.

McCracken C, Zane A, Knight DA, Dutta PK, Waldman WJ. 2013. Minimal intestinal epithelial cell toxicity in response to short- and long-term food-relevant inorganic nanoparticle exposure. Chem Res Toxicol 26:1514-25.

Mercuri A, Passalacqua A, Wickham MS, Faulks RM, Craig DQ, Barker SA. 2011. The effect of composition and gastric conditions on the selfemulsification process of ibuprofen-loaded self-emulsifying drug delivery systems: a microscopic and dynamic gastric model study. Pharm Res 28:1540-51.

Meresse B, Malamut G, Cerf-Bensussan N. 2012. Celiac disease: an immunological jigsaw. Immunity 36:907-19.

Minekus M, Smeets-Peeters M, Bernalier A, Marol-Bonnin S, Havenaar R, Marteau P, et al. 1999. A computer-controlled system to simulate conditions of the large intestine with peristaltic mixing, water absorption and absorption of fermentation products. Appl Microbiol Biotechnol 53:108-14.

Miret S, Abrahamse L, de Groene EM. 2004. Comparison of in vitro models for the prediction of compound absorption across the human intestinal mucosa. J Biomol Screen 9:598-606.

Misra SK, Dybowska A, Berhanu D, Luoma SN, Valsami-Jones E. 2012. The complexity of nanoparticle dissolution and its importance in nanotoxicological studies. Sci Total Environ 438:225-32.

Mizoguchi A. 2012. Animal models of inflammatory bowel disease. Prog Mol Biol Transl Sci 105:263-320.

Moda TL, Andricopulo AD. 2012. Consensus hologram QSAR modeling for the prediction of human intestinal absorption. Bioorg Med Chem Lett 22:2889-93.

Moharamzadeh K, Brook IM, Van Noort R, Scutt AM, Smith KG, Thornhill MH. 2008. Development, optimization and characterization of a full-thickness tissue engineered human oral mucosal model for biological assessment of dental biomaterials. J Mater Sci Mater Med 19:1793-801.

Molly K, Vande Woestyne M, Verstraete W. 1993. Development of a 5step multi-chamber reactor as a simulation of the human intestinal microbial ecosystem. Appl Microbiol Biotechnol 39:254-8.

Mwilu SK, El Badawy AM, Bradham K, Nelson C, Thomas D, Scheckel KG, et al. 2013. Changes in silver nanoparticles exposed to human synthetic stomach fluid: effects of particle size and surface chemistry. Sci Total Environ 447:90-8.

Natoli M, Leoni BD, D’Agnano I, Zucco F, Felsani A. 2012. Good Caco-2 cell culture practices. Toxicol In Vitro 26:1243-6.

Nel AE, Nasser E, Godwin H, Avery D, Bahadori T, Bergeson L, et al. 2013. A multi-stakeholder perspective on the use of alternative test strategies for nanomaterial safety assessment. ACS Nano 7: 6422-33.

Neun BW, Dobrovolskaia MA. 2011. Detection and quantitative evaluation of endotoxin contamination in nanoparticle formulations by LALbased assays. Methods Mol Biol 697:121-30.
Neurath MF. 2012. Animal models of inflammatory bowel diseases: illuminating the pathogenesis of colitis, ileitis and cancer. Dig Dis 30 $1: 91-4$.

Noonan GO, Whelton AJ, Carlander D, Duncan TV. 2014. Measurement methods to evaluate engineered nanomaterial release from food contact materials. Compr Rev Food Sci Food Safety 13:679-92.

Nwokolo CU, Lewin JF, Hudson M, Pounder RE. 1992. Transmucosal penetration of bismuth particles in the human stomach. Gastroenterology 102:163-7.

OECD. 2000. Guidance document on recognition, assessment and use of clinical signs as humane endpoints for experimental animals used in safety evaluation. OECD environmental health and safety publications ENV/JM/MONO:No 19.

OECD. 2010. Toxicokinetics. OECD Guideline for the testing of chemicals Section 4:417.

OECD. 2012. Guidance on sample preparation and dosimetry for the safety testing of manufactured nanomaterials. OECD Environmental Health and Safety Publications ENV/JM/MONO:No 40.

Paek HJ, Lee YJ, Chung HE, Yoo NH, Lee JA, Kim MK, et al. 2013. Modulation of the pharmacokinetics of zinc oxide nanoparticles and their fates in vivo. Nanoscale 5:11416-27.

Paixao P, Gouveia LF, Morais JA. 2012. Prediction of the human oral bioavailability by using in vitro and in silico drug related parameters in a physiologically based absorption model. Int J Pharm 429:84-98.

Park K, Park EJ, Chun IK, Choi K, Lee SH, Yoon J, Lee BC. 2011. Bioavailability and toxicokinetics of citrate-coated silver nanoparticles in rats. Arch Pharm Res 34:153-8.

Patel N, Forbes B, Eskola S, Murray J. 2006. Use of simulated intestinal fluids with Caco-2 cells and rat ileum. Drug Dev Ind Pharm 32: 151-61.

Pelkonen O, Boobis AR, Gundert-Remy U. 2001. In vitro prediction of gastrointestinal absorption and bioavailability: an experts' meeting report. Eur J Clin Pharmacol 57:621-9.

Peters R, Kramer E, Oomen AG, Rivera ZE, Oegema G, Tromp PC, et al. 2012. Presence of nano-sized silica during in vitro digestion of foods containing silica as a food additive. ACS Nano 6:2441-51.

Powell JJ, Ainley CC, Harvey RS, Mason IM, Kendall MD, Sankey EA, et al. 1996. Characterisation of inorganic microparticles in pigment cells of human gut associated lymphoid tissue. Gut 38:390-5.

Powell JJ, Faria N, Thomas-McKay E, Pele LC. 2010. Origin and fate of dietary nanoparticles and microparticles in the gastrointestinal tract. J Autoimmun 34:J226-33.

Prieto P, Hoffmann S, Tirelli V, Tancredi F, Gonzalez I, Bermejo M, De Angelis I. 2010. An exploratory study of two Caco-2 cell models for oral absorption: a report on their within-laboratory and betweenlaboratory variability, and their predictive capacity. Altern Lab Anim 38:367-86.

Pusch J, Votteler M, Gohler S, Engl J, Hampel M, Walles H, SchenkeLayland K. 2011. The physiological performance of a three-dimensional model that mimics the microenvironment of the small intestine. Biomaterials 32:7469-78.

Raju J. 2008. Azoxymethane-induced rat aberrant crypt foci: relevance in studying chemoprevention of colon cancer. World J Gastroenterol 14: 6632-5.

Raju J, Bird RP. 2003. Energy restriction reduces the number of advanced aberrant crypt foci and attenuates the expression of colonic transforming growth factor beta and cyclooxygenase isoforms in Zucker obese (fa/fa) rats. Cancer Res 63:6595-01.

Rappaport SM. 2012. Biomarkers intersect with the exposome. Biomarkers 17:483-9.

Rein MJ, Renouf M, Cruz-Hernandez C, Actis-Goretta L, Thakkar SK, da Silva Pinto M. 2013. Bioavailability of bioactive food compounds: a challenging journey to bioefficacy. Br J Clin Pharmacol 75:588-602.

Reis JM, Sinko B, Serra CH. 2010. Parallel artificial membrane permeability assay (PAMPA) - is it better than Caco-2 for human passive permeability prediction? Mini Rev Med Chem 10:1071-6.

Rickman C, Medine CN, Bergmann A, Duncan RR. 2007. Functionally and spatially distinct modes of munc18-syntaxin 1 interaction. J Biol Chem 282:12097-103.

Roblegg E, Frohlich E, Meindl C, Teubl B, Zaversky M, Zimmer A. 2012. Evaluation of a physiological in vitro system to study the transport of nanoparticles through the buccal mucosa. Nanotoxicology 6:399-413.

Rogers KR, Bradham K, Tolaymat T, Thomas DJ, Hartmann T, Ma L, Williams A. 2012. Alterations in physical state of silver nanoparticles exposed to synthetic human stomach fluid. Sci Total Environ 420: $334-9$. 
Rouleau L, Berti R, Ng VW, Matteau-Pelletier C, Lam T, Saboural P, et al. 2013. VCAM-1-targeting gold nanoshell probe for photoacoustic imaging of atherosclerotic plaque in mice. Contrast Media Mol Imaging 8:27-39.

Rozehnal V, Nakai D, Hoepner U, Fischer T, Kamiyama E, Takahashi M, et al. 2012. Human small intestinal and colonic tissue mounted in the ussing chamber as a tool for characterizing the intestinal absorption of drugs. Eur J Pharm Sci 46:367-73.

Rubas W, Cromwell ME, Shahrokh Z, Villagran J, Nguyen TN, Wellton $\mathrm{M}$, et al. 1996. Flux measurements across Caco-2 monolayers may predict transport in human large intestinal tissue. J Pharm Sci 85: 165-9.

Rubenstein EB, Peterson DE, Schubert M, Keefe D, McGuire D, Epstein J, et al. 2004. Clinical practice guidelines for the prevention and treatment of cancer therapy-induced oral and gastrointestinal mucositis. Cancer 100:2026-46.

Russell TL, Berardi RR, Barnett JL, Dermentzoglou LC, Jarvenpaa KM, Schmaltz SP, Dressman JB. 1993. Upper gastrointestinal ph in seventynine healthy, elderly, north american men and women. Pharm Res 10: 187-96.

Salles C, Tarrega A, Mielle P, Maratray J, Gorria P, Liaboeuf J, Liodenot JJ. 2007. Development of a chewing simulator for food breakdown and the analysis of in vitro flavor compound release in a mouth environment. J Food Eng 82:189-98.

Salman HH, Gamazo C, Agueros M, Irache JM. 2007. Bioadhesive capacity and immunoadjuvant properties of thiamine-coated nanoparticles. Vaccine 25:8123-32.

Sambuy Y, De Angelis I, Ranaldi G, Scarino ML, Stammati A, Zucco F. 2005. The Caco-2 cell line as a model of the intestinal barrier: influence of cell and culture-related factors on Caco-2 cell functional characteristics. Cell Biol Toxicol 21:1-26.

Sandri G, Bonferoni MC, Rossi S, Ferrari F, Gibin S, Zambito Y, et al. 2007. Nanoparticles based on n-trimethylchitosan: evaluation of absorption properties using in vitro (Caco-2 cells) and ex vivo (excised rat jejunum) models. Eur J Pharm Biopharm 65:68-77.

Schmidt C, Lautenschlaeger C, Collnot EM, Schumann M, Bojarski C, Schulzke JD, et al. 2013. Nano- and microscaled particles for drug targeting to inflamed intestinal mucosa: a first in vivo study in human patients. J Control Release 165:139-45.

Shahbazi MA, Santos HA. 2013. Improving oral absorption via drugloaded nanocarriers: absorption mechanisms, intestinal models and rational fabrication. Curr Drug Metab 14:28-56.

Singh G, Stephan C, Westerhoff P, Carlander D, Duncan TV. 2014. Measurement methods to detect, characterize, and quantify engineered nanomaterials in foods. Compr Rev Food Sci Food Saf 13:693-704

Sinha VK, Snoeys J, Osselaer NV, Peer AV, Mackie C, Heald D. 2012. From preclinical to human - prediction of oral absorption and drugdrug interaction potential using physiologically based pharmacokinetic (PBPK) modeling approach in an industrial setting: a workflow by using case example. Biopharm Drug Dispos 33:111-21.

Sonaje K, Chuang EY, Lin KJ, Yen TC, Su FY, Tseng MT, Sung HW. 2012. Opening of epithelial tight junctions and enhancement of paracellular permeation by chitosan: microscopic, ultrastructural, and computed-tomographic observations. Mol Pharm 9:1271-9.

Souliman S, Beyssac E, Cardot JM, Denis S, Alric M. 2007. Investigation of the biopharmaceutical behavior of theophylline hydrophilic matrix tablets using USP methods and an artificial digestive system. Drug Dev Ind Pharm 33:475-83.

Souliman S, Blanquet S, Beyssac E, Cardot JM. 2006. A level a in vitro/ in vivo correlation in fasted and fed states using different methods: applied to solid immediate release oral dosage form. Eur J Pharm Sci 27:72-9.

Sozer N, Kokini JL. 2009. Nanotechnology and its applications in the food sector. Trends Biotechnol 27:82-9.

Stone V, Pozzi-Mucelli S, Tran L, Aschberger K, Sabella S, Vogel U, et al. 2014. ITS-NANO - prioritising nanosafety research to develop a stakeholder driven intelligent testing strategy. Part Fibre Toxicol 11:9. doi:10.1186/1743-8977-11-9.

Suenderhauf C, Hammann F, Maunz A, Helma C, Huwyler J. 2011. Combinatorial QSAR modeling of human intestinal absorption. Mol Pharm 8:213-24.

Sugano K. 2009. Introduction to computational oral absorption simulation. Exp Opin Drug Metab Toxicol 5:259-93.

Szakal C, Roberts SM, Westerhoff P, Bartholomaeus A, Buck N, Illuminato I, et al. (2014a). Measurement of nanomaterials in foods: integrative consideration of challenges and future prospects. ACS Nano $8: 3128-35$.

Szakal C, Tsytsikova L, Carlander D, Duncan TV. (2014b). Measurement methods for the oral uptake of engineered nanomaterials from human dietary sources: summary and outlook. Compr Rev Food Sci Food Saf 13:669-78.

Tanaka T. 2012. Animal models of carcinogenesis in inflamed colorectum: potential use in chemoprevention study. Curr Drug Targets 13:1689-97.

Tavelin S, Taipalensuu J, Soderberg L, Morrison R, Chong S, Artursson P. 2003. Prediction of the oral absorption of low-permeability drugs using small intestine-like 2/4/a1 cell monolayers. Pharm Res 20: 397-405.

Teeguarden JG, Hinderliter PM, Orr G, Thrall BD, Pounds JG. 2007. Particokinetics in vitro: dosimetry considerations for in vitro nanoparticle toxicity assessments. Toxicol Sci 95:300-12.

Teubl BJ, Absenger M, Frohlich E, Leitinger G, Zimmer A, Roblegg E. 2013. The oral cavity as a biological barrier system: design of an advanced buccal in vitro permeability model. Eur J Pharm Biopharm 84:386-93.

Thomas C, Oates PS. 2002. IEC-6 cells are an appropriate model of intestinal iron absorption in rats. J Nutr 132:680-7.

Thomas K, Aalbers M, Bannon GA, Bartels M, Dearman RJ, Esdaile DJ, et al. 2004. A multi-laboratory evaluation of a common in vitro pepsin digestion assay protocol used in assessing the safety of novel proteins. Regul Toxicol Pharmacol 39:87-98.

Tryndyak V, de Conti A, Kobets T, Kutanzi K, Koturbash I, Han T, et al. 2012. Interstrain differences in the severity of liver injury induced by a choline- and folate-deficient diet in mice are associated with dysregulation of genes involved in lipid metabolism. FASEB J 26: 4592-602.

Tyrer P, Ruth Foxwell A, Kyd J, Harvey M, Sizer P, Cripps A. 2002. Validation and quantitation of an in vitro M-cell model. Biochem Biophys Res Commun 299:377-83.

Valerio Jr LG, Balakrishnan S, Fiszman ML, Kozeli D, Li M, Moghaddam S, Sadrieh N. 2013. Development of cardiac safety translational tools for QT prolongation and torsade de pointes. Exp Opin Drug Metab Toxicol 9:801-15.

Van de Wiele TR, Oomen AG, Wragg J, Cave M, Minekus M, Hack A, et al. 2007. Comparison of five in vitro digestion models to in vivo experimental results: lead bioaccessibility in the human gastrointestinal tract. J Environ Sci Health A Tox Hazard Subst Environ Eng 42: 1203-11.

van der Zande M, Vandebriel RJ, Van Doren E, Kramer E, Herrera Rivera Z, Serrano-Rojero CS, et al. 2012. Distribution, elimination, and toxicity of silver nanoparticles and silver ions in rats after 28-day oral exposure. ACS Nano 6:7427-42.

Vergeres G, Bogicevic B, Buri C, Carrara S, Chollet M, CorbinoGiunta L, et al. 2012. The nutrichip project-translating technology into nutritional knowledge. Br J Nutr 108:762-8.

Versantvoort CH, Ondrewater RC, Duizer E, Van de Sandt JJ, Gilde AJ, Groten JP. 2002. Monolayers of IEC-18 cells as an in vitro model for screening the passive transcellular and paracellular transport across the intestinal barrier: comparison of active and passive transport with the human colon carcinoma Caco-2 cell line. Environ Toxicol Pharmacol 11:335-44.

Versantvoort CH, Oomen AG, Van de Kamp E, Rompelberg CJ, Sips AJ. 2005. Applicability of an in vitro digestion model in assessing the bioaccessibility of mycotoxins from food. Food Chem Toxicol 43: 31-40.

Volpe DA. 2010. Application of method suitability for drug permeability classification. AAPS J 12:670-8.

Walczak AP, Fokkink R, Peters R, Tromp P, Herrera Rivera ZE, Rietjens IM, et al. 2013. Behaviour of silver nanoparticles and silver ions in an in vitro human gastrointestinal digestion model. Nanotoxicology 7: 1198-210.

Walter E, Janich S, Roessler BJ, Hilfinger JM, Amidon GL. 1996. HT29MTX/Caco-2 cocultures as an in vitro model for the intestinal epithelium: in vitro-in vivo correlation with permeability data from rats and humans. J Pharm Sci 85:1070-6.

Wang C, Qiao L, Zhang Q, Yan H, Liu K. 2012. Enhanced cell uptake of superparamagnetic iron oxide nanoparticles through direct chemisorption of FITC-TaT-PEG 600 -b-poly(glycerol monoacrylate). Int J Pharm 430:372-80.

Watson C, Ge J, Cohen J, Pyrgiotakis G, Engelward BP, Demokritou P. 2014. High-throughput screening platform for engineered nanoparticle- 
mediated genotoxicity using comet chip technology. ACS Nano 8: 2118-33.

Wickham M, Faulks R, Mills C. 2009. In vitro digestion methods for assessing the effect of food structure on allergen breakdown. Mol Nutr Food Res 53:952-8.

Will OC, Man RF, Phillips RK, Tomlinson IP, Clark SK. 2008. Familial adenomatous polyposis and the small bowel: a loco-regional review and current management strategies. Pathol Res Pract 204: 449-58.

Winkler DA, Mombelli E, Pietroiusti A, Tran L, Worth A, Fadeel B, McCall MJ. 2012. Applying quantitative structure-activity relationship approaches to nanotoxicology: current status and future potential. Toxicology 313:15-23.

Yada R, Buck N, Canady C, DeMerlis C, Duncan T, Janer G, et al. 2014. Engineered nanoscale food ingredients: evaluation of current knowledge on material characteristics relevant to uptake from the gastrointestinal tract. Compr Rev Food Sci Food Saf 13:730-44.

Yadev NP, Murdoch C, Saville SP, Thornhill MH. 2011. Evaluation of tissue engineered models of the oral mucosa to investigate oral candidiasis. Microb Pathog 50:278-85.

Yan YD, Woo JS, Kang JH, Yong CS, Choi HG. 2010. Preparation and evaluation of taste-masked donepezil hydrochloride orally disintegrating tablets. Biol Pharm Bull 33:1364-70.

Youdim KA, Avdeef A, Abbott NJ. 2003. In vitro trans-monolayer permeability calculations: often forgotten assumptions. Drug Discov Today 8:997-1003.
Yu J, Peng S, Luo D, March JC. 2012. In vitro 3D human small intestinal villous model for drug permeability determination. Biotechnol Bioeng 109:2173-8.

Yu LX, Amidon GL. 1999. A compartmental absorption and transit model for estimating oral drug absorption. Int J Pharm 186: 119-25.

Yuan H, Chen CY, Chai GH, Du YZ, Hu FQ. 2013. Improved transport and absorption through gastrointestinal tract by pegylated solid lipid nanoparticles. Mol Pharm 10:1865-73.

Yuan H, Chen J, Du YZ, Hu FQ, Zeng S, Zhao HL. 2007. Studies on oral absorption of stearic acid SLN by a novel fluorometric method. Colloids Surf B Biointerfaces 58:157-64.

Zariwala MG, Elsaid N, Jackson TL, Corral Lopez F, Farnaud S, Somavarapu S, Renshaw D. 2013. A novel approach to oral iron delivery using ferrous sulphate loaded solid lipid nanoparticles. Int $\mathbf{J}$ Pharm 456:400-7.

Zeineldin M, Neufeld KL. 2013. More than two decades of Apc modeling in rodents. Biochim Biophys Acta 1836:80-9.

Zhang S, Moss SF. 2012. Rodent models of helicobacter infection, inflammation, and disease. Methods Mol Biol 921: 89-98.

Zolotarevsky Y, Hecht G, Koutsouris A, Gonzalez DE, Quan C, Tom J, et al. 2002. A membrane-permeant peptide that inhibits MLC kinase restores barrier function in in vitro models of intestinal disease. Gastroenterology 123:163-72. 